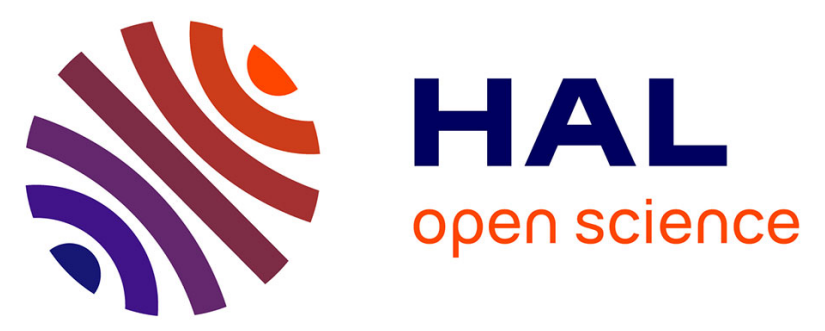

\title{
Massive Intracellular Remodeling of CuS Nanomaterials Produces Nontoxic Bioengineered Structures with Preserved Photothermal Potential
}

Alberto Curcio, Aurore Van de Walle, Emilia Benassai, Aida Serrano, Nathalie Luciani, Nicolas Menguy, Bella B Manshian, Ara Sargsian, Stefaan Soenen, Ana Espinosa, et al.

\section{To cite this version:}

Alberto Curcio, Aurore Van de Walle, Emilia Benassai, Aida Serrano, Nathalie Luciani, et al.. Massive Intracellular Remodeling of CuS Nanomaterials Produces Nontoxic Bioengineered Structures with Preserved Photothermal Potential. ACS Nano, In press, 10.1021/acsnano.1c00567 . hal-03237430

\section{HAL Id: hal-03237430 \\ https://hal.sorbonne-universite.fr/hal-03237430}

Submitted on 26 May 2021

HAL is a multi-disciplinary open access archive for the deposit and dissemination of scientific research documents, whether they are published or not. The documents may come from teaching and research institutions in France or abroad, or from public or private research centers.
L'archive ouverte pluridisciplinaire HAL, est destinée au dépôt et à la diffusion de documents scientifiques de niveau recherche, publiés ou non, émanant des établissements d'enseignement et de recherche français ou étrangers, des laboratoires publics ou privés. 


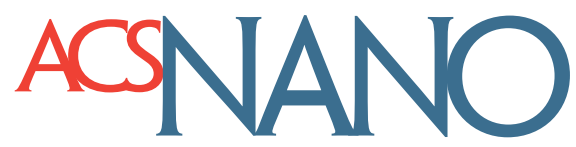

\title{
Massive Intracellular Remodeling of CuS Nanomaterials Produces Nontoxic Bioengineered Structures with Preserved Photothermal Potential
}

\author{
${ }_{5}$ Alberto Curcio, Aurore Van de Walle, Emilia Benassai, Aida Serrano, Nathalie Luciani, Nicolas Menguy,
} ${ }_{6}$ Bella B. Manshian, Ara Sargsian, Stefaan Soenen, Ana Espinosa, Ali Abou-Hassan,* and Claire Wilhelm*

Cite This: https://doi.org/10.1021/acsnano.1c00567

Read Online

7 ABSTRACT: Despite efforts in producing nanoparticles with 8 tightly controlled designs and specific physicochemical proper9 ties, these can undergo massive nano-bio interactions and 10 bioprocessing upon internalization into cells. These trans11 formations can generate adverse biological outcomes and 12 premature loss of functional efficacy. Hence, understanding 13 the intracellular fate of nanoparticles is a necessary prerequisite 14 for their introduction in medicine. Among nanomaterials 15 devoted to theranostics are copper sulfide $(\mathrm{CuS})$, which 16 provides outstanding optical properties along with easy 17 synthesis and low cost. Herein, we performed a long-term 18 multiscale study on the bioprocessing of hollow $\mathrm{CuS}$ nano-

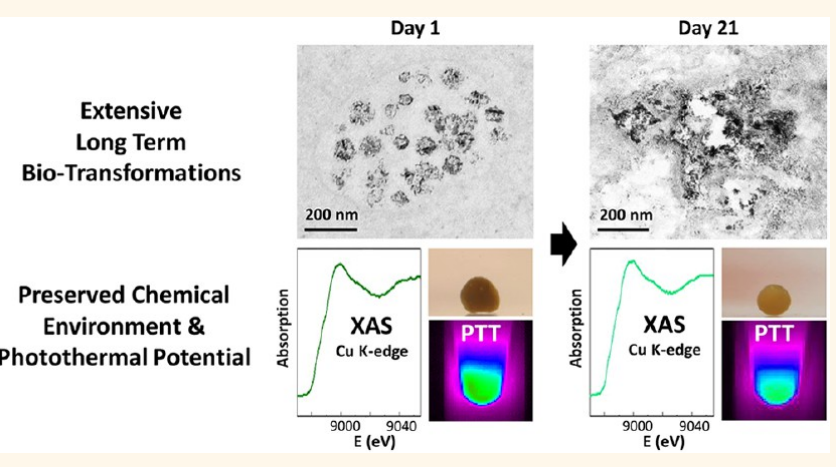
19 particles (CuS NPs) and rattle-like iron oxide nanoflowers@

${ }_{20} \mathrm{CuS}$ core-shell hybrids (IONF@CuS NPs) when inside stem cells and cancer cells, cultured as spheroids. In the spheroids, 21 both CuS NPs and IONF@CuS NPs are rapidly dismantled into smaller units (day 0 to 3 ), and hair-like nanostructures are 22 generated (days 9-21). This bioprocessing triggers an adaptation of the cellular metabolism to the internalized metals without 23 impacting cell viability, differentiation, or oxidative stress response. Throughout the remodeling, a loss of IONF-derived 24 magnetism is observed, but, surprisingly, the $\mathrm{CuS}$ photothermal potential is preserved, as demonstrated by a full 25 characterization of the photothermal conversion across the bioprocessing process. The maintained photothermal efficiency 26 correlated well with synchrotron X-ray absorption spectroscopy measurements, evidencing a similar chemical phase for Cu but 27 not for Fe over time. These findings evidence that the intracellular bioprocessing of $\mathrm{CuS}$ nanoparticles can reshape them into 28 bioengineered nanostructures without reducing the photothermal function and therapeutic potential.

29 KEYWORDS: biodegradation, biocompatibility, biosynthesis, CuS nanoparticles, magnetic nanoparticles, photothermia

30 norganic nanohybrids are designed with multiple capa-
31
bilities, which are tailored for specific therapeutic or
diagnostic purpose, and assembled all-in-one. The
33 complex architectures of these nanomaterials imply a
34 coexistence of multiple compositions, a control of size and
35 shape, and a stabilization and functionalization via surface
36 coating, altogether to provide original biomedical solutions.
37 Their pursued aptitudes include detection, ${ }^{2}$ therapeutic
38 efficiency with synergistic multifunction, ${ }^{3-7}$ and safety.
39 Importantly, one major issue these engineered nanohybrids
40 have to face is their possible modifications once in the complex
41 biological environment, such as the formation of a protein
42 corona inside blood circulation. ${ }^{11-14}$ Moreover, an increasing number of studies demonstrated that inorganic nanoparticles 43 (NPs) can also undergo drastic changes, such as intracellular 44 degradation, upon endocytosis into the endosomal/lysosomal 45 compartments. $^{15-22}$ One of the most commonly studied NPs 46 are the magnetic ones, based on an iron oxide core. In this 47 case, the core degradation translates into a loss of the magnetic 48

Received: January 20, 2021

Accepted: May 12, 2021 

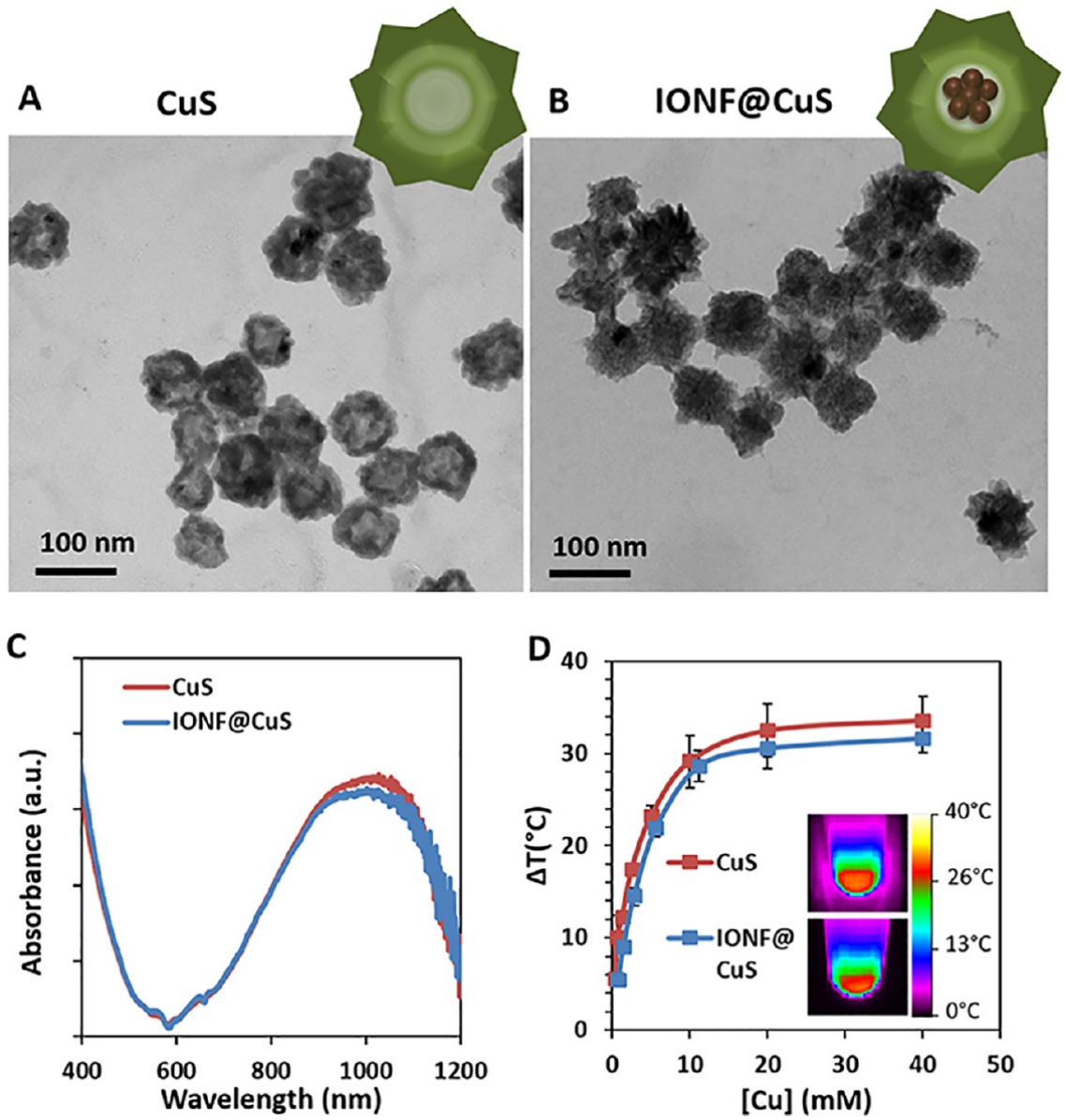

Figure 1. Copper sulfide nanoassemblies. (A, B) Transmission electron microscopy (TEM) images of hollow substoichiometric Cu $\mathrm{u}_{2-x} \mathrm{~S}$ NPs (B) and rattle-like NPs composed of an IONF core bearing a $\mathrm{Cu}_{2-x} \mathrm{~S}$ assembly shell. (C) Absorbance spectra showing a similar near NIR absorption band around $1000 \mathrm{~nm}$. (D) Comparative analysis of the heating of a $10 \mu \mathrm{L} \mathrm{NP}$ suspension at increasing concentration from [Cu] $=0.1$ to $40 \mathrm{mM}$, upon laser exposure at $1064 \mathrm{~nm}$ and $0.3 \mathrm{~W} \mathrm{~cm}$ laser power density, for a 5 min duration. Representative infrared (IR) thermographic camera images are shown in the inset for $[\mathrm{Cu}]=20 \mathrm{mM}$.

49 properties. $^{23}$ The loss of magnetism implies a decreased 50 efficiency for their biomedical applications ${ }^{24}$ as imaging and 51 therapeutic agents. Other types of NP composition, such as 52 plasmonic silver, have also been reported to undergo 53 intracellular degradation, leading to a drastic loss of the 54 photothermal therapy (PTT) potential. ${ }^{25}$ The magnetic or the 55 silver cores covered with gold ${ }^{25,26}$ or polymeric ${ }^{23,27}$ shells can 56 then act as a shield against degradation and favor maintenance 57 of magnetic or plasmonic therapeutic functions. Some studies 58 also reported the fate of NP coating in vivo, where a clear 59 dismantling of the nanostructures emerged after circulation in 60 the organism. ${ }^{28,29}$ Upon biodegradation, the nanoparticle core 61 dissolution induces the release of ions (typically iron or silver), 62 which prompts an adaptation of the cellular metabolism. The 63 released ions were generally stored in the ferritin protein, ${ }^{25,30}$ 64 but could also be used for generation of newly biomineralized 65 magnetic nanoparticles. ${ }^{30,31}$

66 Among the multifunctional NPs that are particularly 67 promising for the biomedical field, those based on copper 68 sulfide $(\mathrm{CuS})$ are emerging as a promising class with numerous 69 therapeutic features. ${ }^{32-34}$ Their light-to-heat conversion 70 efficiencies are among the highest, ${ }^{33,35}$ and they provide dual 71 laser-mediated treatments for both photothermal and photo72 dynamic therapies in the most preferred second near-infrared 73 biological window, ${ }^{33,34,36}$ situated between 1000 and $1700 \mathrm{~nm}$, appealing for its deep penetration, low optical absorption and 74 scattering from biological substrates, and low tissue auto- 75 fluorescence. One of the peculiar aspects of CuS-based 76 materials resides in the origin of their optical absorption, 77 which is responsible for their photothermal conversion and is 78 still under debate. While some attributed such absorption to 79 plasmonic effects resulting from free hole oscillations in the 80 semiconductor, others assigned it to a valence band transition, 81 independent from the solvent or the surrounding environment, 82 as opposed to plasmonic NPs, but both mainly governed by 83 the chemical composition of NPs. ${ }^{37,38}$

Hollow CuS-based nanostructures have received increasing 85 interest in the field of nanomedicine over the last years. They 86 can be used as cargos for drug delivery applications due to their 87 hollow porous organization and for thermal therapy thanks to 88 their physical plasmonic properties. ${ }^{39,40}$ By comparison to 89 other $\mathrm{CuS}$ nanoparticles, the sacrificial templating method 90 used for the synthesis of hollow $\mathrm{CuS}$ nanostructures is green 91 (water $/ 70^{\circ} \mathrm{C}$ ) and reproducible and can be easily scaled up to 92 meet biomedical applications. Finally, the same methodology 93 can be transposed for growing hollow copper sulfide shells of 94 the same morphology and composition (core and surface) 95 around any inorganic core, such as one composed of magnetic 96 nanoparticles, what makes them even more attractive. Very 97 recently, we have demonstrated that rattle-like magnetic iron 98 
99 oxides@CuS nanohybrids are promising theranostic agents. ${ }^{33}$ 100 Considering all these advantages, it appears that the biofate 101 and bioprocessing of such nanomaterials inside cells and their 102 impact on their physical theranostic properties should be 103 investigated. To date, few studies have explored the 104 biodegradation of $\mathrm{CuS}$ structures. Those were performed in $105 v^{2} v^{40}$ or in acidic- and ionic-based environments mimicking 106 the lysosomal content ${ }^{41}$ and evidenced the bioinstability of $107 \mathrm{CuS}$-based nanomaterials. This instability has yet to be 108 explored within living cells.

109 Here, we propose a tissue model based on human 110 mesenchymal stem cells to explore in depth the long-term 111 intracellular fate of $\mathrm{CuS}$, synthesized as nanoassemblies. This 112 3D cellular model, organized in a compact spheroid form, 113 allows the quantitative monitoring of NPs' functional activities 114 and structural transformations over almost a month. Hollow $115 \mathrm{CuS}$ nanoassemblies and rattle-like hybrids featuring an iron 116 oxide nanoflower (IONF) core and a $\mathrm{CuS}$ shell were 117 investigated. The latter nanostructure allows both the analysis 118 of a combined $\mathrm{CuS} /$ iron oxide transformation and also the use 119 of the magnetic core as a tracer of the degradation. Cellular 120 uptake and toxicity screening including reactive oxygen species 121 (ROS) production and impact on stem cell differentiation were 122 conducted upstream. Electron microscopy was employed to 123 observe the intracellular structural evolution of the nanoma124 terials, highlighting an extensive structural instability. Near 125 infrared photoinduced heating (light-to-heat conversion 126 efficiency) was monitored alongside the biological processing, 127 to provide information on the evolution of the functional 128 potential and thus its time-scale range of applicability. 129 Unexpectedly, almost no loss of photothermal potential was 130 detected over the whole period of analysis (21 days). This 131 observation was confirmed in cancer cell spheroids. Con132 versely, an almost total loss of magnetism was revealed in the 133 case of the $\mathrm{CuS} /$ iron oxide nanohybrids (IONF@CuS). A final 134 proof brought by X-ray absorption spectroscopy (XAS) 135 measurements at the spheroid scale at the $\mathrm{Fe}$ and $\mathrm{Cu}$ K-edge 136 energies confirmed a strong modification of the iron chemical 137 environment, but no significant change in the copper one. 138 Thus, we demonstrate here an intracellular processing of 139 copper-based nanomaterials featuring both a massive structural 140 transformation and the preservation of its functional physical 141 properties. On a practical level, $\mathrm{CuS}$ nanoassemblies position 142 themselves as efficient photoresponsive nanomaterials that 143 retain their function in a biological environment in the long144 term and despite their biological processing.

\section{RESULTS AND DISCUSSION}

146 Photothermal-Responsive Copper Sulfide Assem147 blies. Substoichiometric hollow $\mathrm{Cu}_{2-x} \mathrm{~S}$ nanoassemblies, 148 hereafter named copper sulfide $(\mathrm{CuS})$, and a rattle-like iron 149 oxide nanoflower core surrounded by copper sulfide assemblies 150(IONF@CuS) were prepared by a two-step water-based 151 template sacrificial synthesis followed by their surface 152 modification with PEG (Figure $1 \mathrm{~A}$ and $\mathrm{B}$, respectively), as 153 described in the Materials and Methods section. ${ }^{33}$ The CuS 154 and IONF@CuS nanoparticles featured an average diameter of $15562 \pm 8 \mathrm{~nm}$ and $68 \pm 9 \mathrm{~nm}$, respectively, measured on 156 transmission electron microscopy (TEM) images. In the case 157 of IONF@CuS, the diameter of the nanoflower-like magnetic 158 core was $24 \pm 5 \mathrm{~nm}$ (typical TEM image shown in Figure S1). 159 Both nanostructures exhibit a similar hydrodynamic size with 160 an average of about $90 \mathrm{~nm}$, stable in cellular media (DLS,
Figure S2), and a similar broad near-infrared (NIR) absorption 161 band centered around $1000 \mathrm{~nm}$ (Figure 1C). Their exposure 162 to a $1064 \mathrm{~nm}$ laser at low power density $\left(0.3 \mathrm{~W} / \mathrm{cm}^{2}\right)$ for 5163 min induced a high temperature elevation (Figure 1D), with, 164 for $[\mathrm{Cu}]$ over $10 \mathrm{mM}$, a $30{ }^{\circ} \mathrm{C}$ temperature increase $\Delta T 165$ reached for both nanoassembly formulations. Figure S3 also 166 provides the calculation of the light-to-heat conversion 167 efficiency, with an average value of $(42 \pm 6) \%$.

168

Internalization and Photothermia in Cells. Hollow 169 $\mathrm{CuS}$ and rattle-like IONF@CuS NPs were internalized in 170 primary human mesenchymal stem cells (hMSCs), selected as 171 a resourceful and versatile model that provides fine 172 biocompatibility information on long-term culture. The CuS 173 and IONF@CuS NPs were incubated for $4 \mathrm{~h}$ with hMSCs at 174 $\mathrm{Cu}$ concentrations ranging from 0.1 to $1.6 \mathrm{mM}$. TEM images 175 show the two stages of internalization. In Figure 2A and B, $176 \mathrm{f} 2$ respectively CuS and IONF@CuS NPs can be seen close to 177 the outer cell membrane, just before their internalization, 178 which is obtained on the $2 \mathrm{D}$ culture in a nonspecific way. 179 Figure 2C-F show both NPs accumulated within the 180 endosomes, with their structural architecture still intact. 181 Additional images are presented in Figure S4 and Figure S5. 182 In the case of IONF@CuS NPs, the iron oxide core is easily 183 recognizable with its nanoflower-like shape and $24 \mathrm{~nm}$ size 184 compared to the surrounding $\mathrm{CuS}$, which appears bigger, 185 forming a hollow shell, as can be seen from the thin 186 longitudinal sectioning of the samples (40 nm slices; Figure 187 $2 \mathrm{~B}$ and F). As emerged from elemental analysis (Figure S6), 188 NP internalization increases with the incubation concentration 189 for both nanoformulations. Once the nanoassemblies were 190 internalized, high-density collected cells (250000 cells in 10191 $\mu \mathrm{L}$, at different intracellular doses) were exposed to photo- 192 thermia, in the same configuration (volume and laser power 193 density) as previously achieved for aqueous dispersions (Figure 194 1). Heating efficiency in the cell environment was found to be 195 similar for both CuS and IONF@CuS NPs (Figure 2G and H) 196 and in the same range as obtained in water (Figure 1D). The 197 photothermal potential of CuS-based NPs is thus similar in an 198 aqueous dispersion or within cells.

199

Biological Responses Using High-Content Imaging. 200 Results of cytotoxicity analyses of cellular interaction with the 201 different NPs for $72 \mathrm{~h}$ investigating cell viability, mitochondrial 202 reactive oxygen species (MitoROS), and the size of the 203 mitochondrial network are presented in Figure 3. Representa- 204 f3 tive images of the InCell analysis experiment for viability and 205 MitoROS are presented in Figure 3D and Figure S7. 206 Altogether, these results indicate that CuS NPs induce toxic 207 effects only at the highest concentrations (Figure 3A). The 208 level of observed cell death was accompanied by only a 209 marginal increase in MitoROS (Figure 3B), while mitochon- 210 drial area (an indicator for mitochondrial stress) displayed a 211 significant reduction in size of the cellular mitochondrial 212 network (Figure 3C). The latter indicates a clear increase in 213 mitochondrial stress, at high concentrations, but this does not 214 seem to be linked to the generation of ROS.

215

Long-Term Impact on Stem Cell Spheroids. In order to 216 perform longer-term toxicity assessment, stem cells labeled 217 with CuS or IONF@CuS NPs (incubated at extracellular [Cu] 218 $=0.4 \mathrm{mM}$ ) were cultured as spheroids for 21 days (Figure 4A). $219 \mathrm{f} 4$ This $3 \mathrm{D}$ model is commonly used for the chondrogenic 220 differentiation of stem cells, which is initiated by both the 3D 221 organization of the cells and the addition of specific culture 222 conditions. It results in an important production of 223 


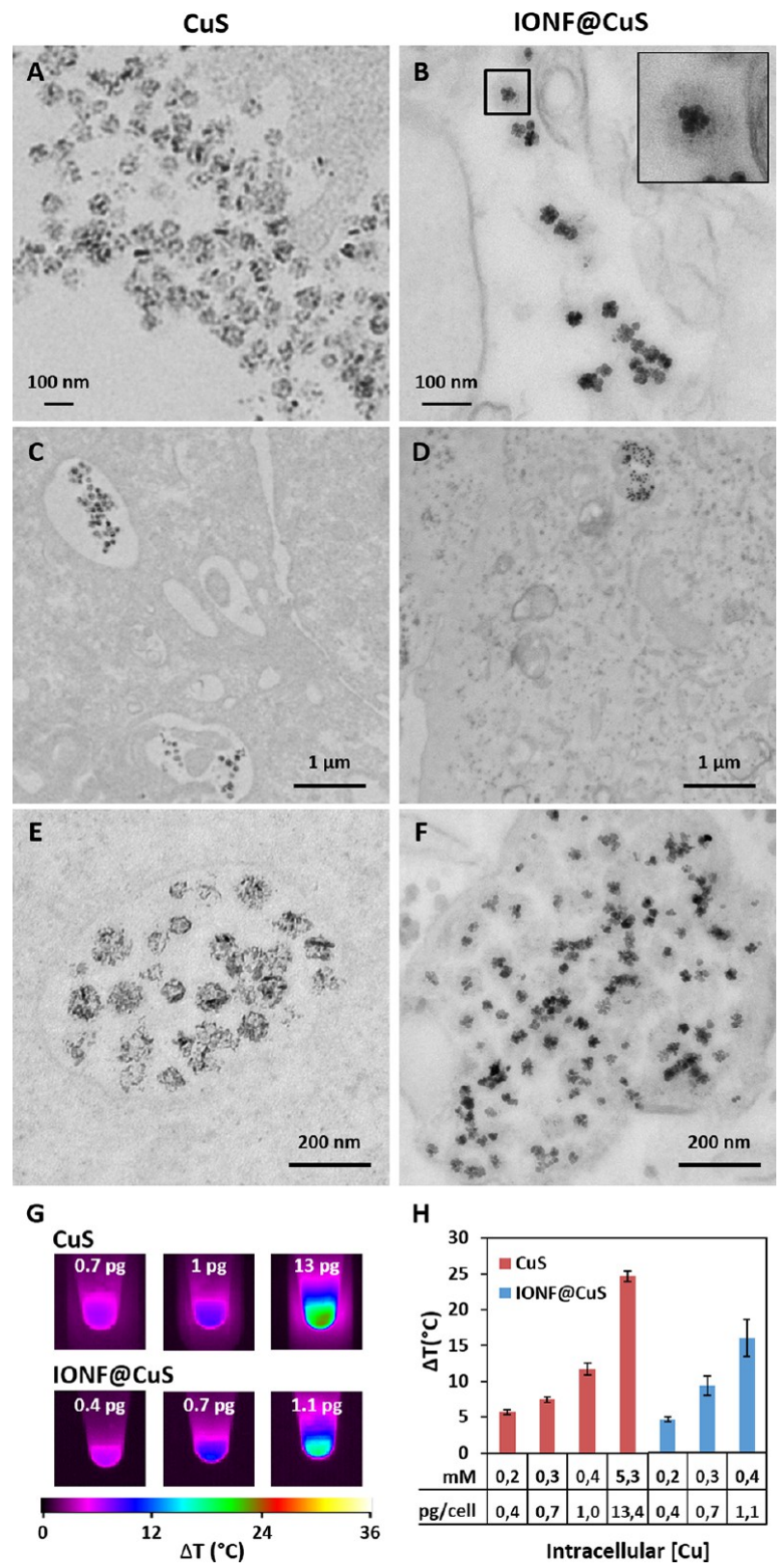

Figure 2. NP internalization in primary stem cells. (A-F) TEM micrographs showing CuS (A, C, E) and IONF@CuS (B, D, F) nanoassemblies upon $4 \mathrm{~h}$ incubation with hMSCs at a Cu concentration of $0.5 \mathrm{mM}$. Some nanoassemblies are still visible at the cell outer membrane before endocytosis (A, B). Most of the nanoassemblies were however already found inside endosomes, where they appear still intact and highly accumulated (C, D, E, F). (G) Representative IR thermographic camera images of a nanoassembly-containing cell suspension $(250000$ cells in 10 $\mu \mathrm{L}$ ) after $5 \mathrm{~min}$ of $1064 \mathrm{~nm}$ laser exposure, at different doses of $\mathrm{Cu}$. For the $\mathrm{CuS}$ (top), the three conditions correspond to extracellular incubation at $[\mathrm{Cu}]=0.2,0.4$, and $1.6 \mathrm{mM}$, resulting in intracellular $\mathrm{Cu}$ amounts of $0.7,1$, and $13.4 \mathrm{pg} \mathrm{Cu}$ per cell, respectively. For the IONF@CuS (bottom), they correspond to $[\mathrm{Cu}]=0.1,0.2$, and $0.4 \mathrm{mM}$, resulting in intracellular $\mathrm{Cu}$ amounts of $0.4,0.7$, and $1.1 \mathrm{pg} \mathrm{Cu}$ per cell, respectively. (H) Average heating of CuS and IONF@CuS treated hMSCs upon $4 \mathrm{~h}$ of incubation, plotted against their intracellular mass of $\mathrm{Cu}$ in $\mathrm{pg}$ per cell ( $x$-axis, bottom) or the resulting molar concentration of $\mathrm{Cu}$ in the $10 \mu \mathrm{L}$ cell dispersion ( $x$-axis, top). extracellular matrix (e.g., collagen II, aggrecan). Importantly, 224 under this setup, cells can remain viable in culture for extensive 225 time frames (even months) without dividing, allowing one to 226 assess the long-term biological impact in a quantitative 227 manner.

Representative TEM images taken at day 21 show that the 229 cells labeled with CuS-based NPs have produced an organized 230 extracellular matrix (Figure 4B), a clear sign of their advanced 231 stage of differentiation. Histology images also confirm an 232 abundance of proteoglycans within these CuS-incorporated 233 spheroids similar to control spheroids, as indicated by positive 234 toluidine blue staining (Figure 4C). Gene expression of 235 cartilage-specific constituents (aggrecan and collagen II) was 236 assessed by qPCR for the spheroids labeled with IONF@CuS 237 NPs and shows an increased expression over time, similar to 238 the control at day 21, confirming the chondrogenic differ- 239 entiation of the cells (Figure S8). Overall, the intracellular 240 presence of CuS-based NPs appears not to hinder the typical 241 biological maturation of the stem cell spheroids.

242

Long-Term Expression of Oxidative Stress and Metal 243 Ion-Related Genes. Biological outcomes of the internal- 244 ization of $\mathrm{CuS}$ and IONF@CuS materials in stem cells 245 cultured as spheroids in the long-term (up to 21 days) were 246 assessed by measuring the expression of genes involved in the 247 oxidative stress response and in copper and iron metabolisms 248 (Figure 5). First, Figure 5A shows the expression of GLRX and $249 \mathrm{fs}$ SOD1 (encoding for glutaredoxin and superoxide dismutase 1, 250 respectively), both involved in the antioxidant defense system, 251 and of NOX2- $\alpha$ (encoding for NADPH oxidase 2), involved in 252 ROS production. The expression of these oxidative stress 253 related genes is not impacted by the presence of the CuS-based 254 NPs. This supports the previous findings (Figure 3B) that no 255 significant mitochondrial ROS were produced. Figure 5B 256 evidences next that most of the copper- and iron-related genes 257 were not upregulated, except for CP, encoding for 258 ceruloplasmin, one of the most important copper carriers 259 also involved in iron metabolism. By contrast, three genes 260 encoding for metallothioneins (involved in the homeostasis of 261 heavy metals, such as copper) are upregulated in a time- 262 dependent manner after exposure to $\mathrm{CuS}$ and IONF@CuS 263 (Figure 5C, D, and E). For the IONF@CuS, upregulation is 264 maximal at day 3 and progressively returns to control levels 265 over time, for all the isoforms analyzed (MT1E, MT1X, and 266 MT2A). For CuS NPs, upregulation is less important at day 3, 267 but remains sustained for longer duration. Hence, metal- 268 lothionein gene expression is induced after exposure to both 269 formulations of CuS-based nanomaterials.

270

Overall, this analysis provides insights into $\mathrm{Cu}$ and $\mathrm{Fe} 271$ metabolic pathways. First it suggests a role of the metal- 272 lothioneins in the cellular response to $\mathrm{Cu}$-based materials. The 273 upregulation of CP for both $\mathrm{CuS}$ and IONF@CuS is 274 consistent with its role not only as $\mathrm{Cu}$ transporter but also 275 for Fe. ${ }^{42}$ The particular case of ATP7A is also relevant, with an 276 upregulation only for IONF@CuS. ATP7A encodes for the 277 copper-transporting ATPase 1 that has for a main function the 278 transport of $\mathrm{Cu}$, and potentially $\mathrm{Fe}$, across the cell membrane, 279 and is thus related to cellular ion levels. ${ }^{43}$

Structural Transformations Observed at the Nano- 281 scale by Electron Microscopy. TEM observations were 282 undertaken throughout the 21 days of spheroid maturation. 283 They evidenced that the integrity of the nanoassemblies is 284 rapidly affected by the biological environment, with structural 285 modifications already starting at the third day of spheroid 286 


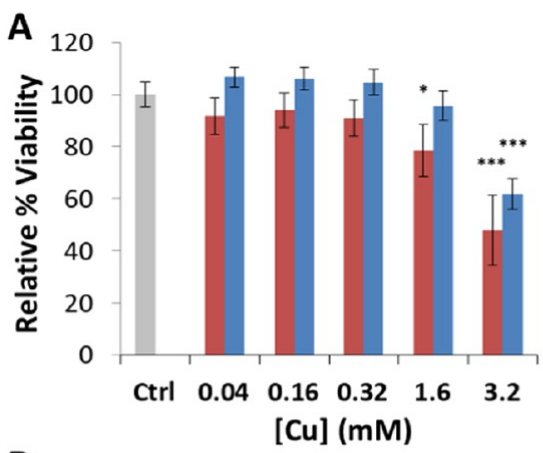

D
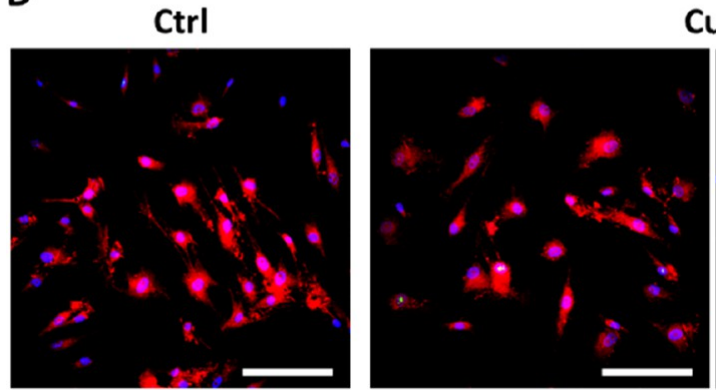

$0.32 \mathrm{mM}$

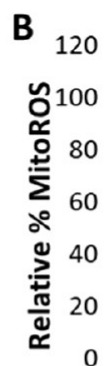

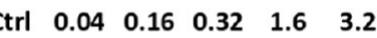
[Cu] (mM)

CuS

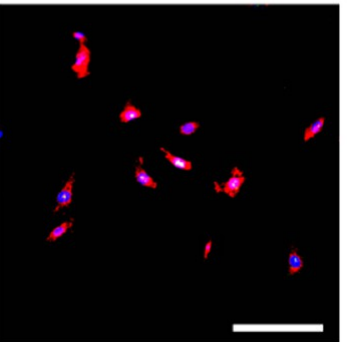

$3.2 \mathrm{mM}$
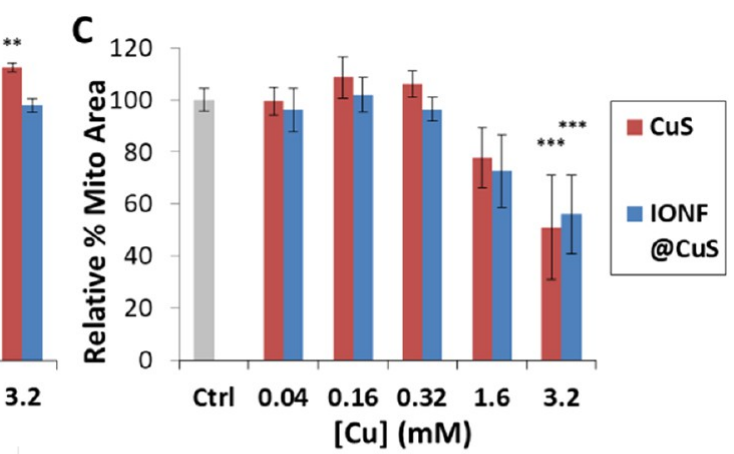

IONF@CuS

Figure 3. Nanotoxicity screening results of hMSC exposed to various concentrations of CuS and IONF@CuS NPs for 72 h. (A) Biocompatibility analysis, (B) mitochondrial ROS, and (C) size of the mitochondrial network of hMSCs treated for $72 \mathrm{~h}$ with CuS and IONF@CuS at concentrations ranging from 0.04 to $3.2 \mathrm{mM}$ of $\mathrm{Cu}$ and relative to untreated control cells $(* p<0.05$, $* * p<0.01$, and $* * * p<$ 0.001). (D) Representative merged images of the hMSCs treated with CuS and IONF@CuS nanoassemblies at 0.32 and $3.2 \mathrm{mM}$ of Cu. Nuclei are stained in red (Hoechst), and dead cells' nuclei are counter-stained in green (as light green spots). For the $3.2 \mathrm{mM}$ conditions, many nuclei appear green labeled. Mitochondrial network stained in red (MitoTracker Red CMXRos) (Scale bar $=200 \mu \mathrm{m})$.

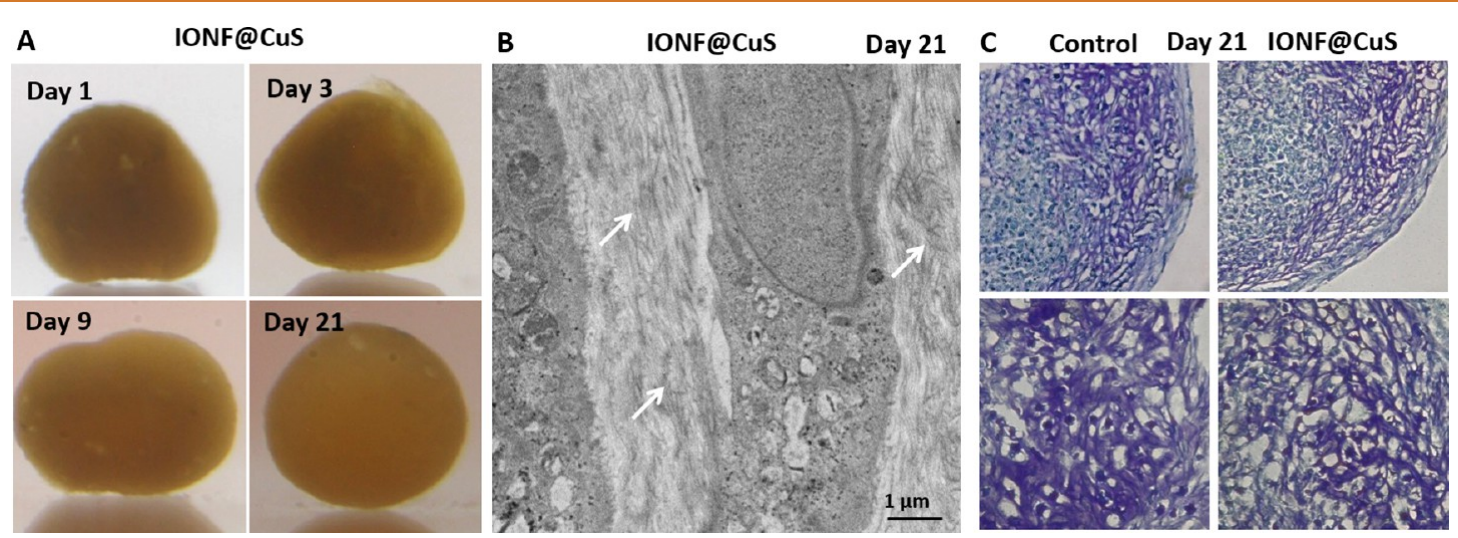

Figure 4. Formation of spheroids from stem cells loaded with CuS-based NPs for long-term culture. (A) Representative photographs of spheroids made of stem cells loaded with IONF@CuS NPs ( $4 \mathrm{~h}$ of incubation at day 0 , with $0.4 \mathrm{mM} \mathrm{Cu}$ ). The spheroids become more cohesive and spherical during the 21-day culture period. (B) TEM image of a spheroid harvested and sectioned at day 21 showing the presence of a dense extracellular matrix in between the cells (white arrows). (C) Histological images of spheroids fixed and sectioned at day 21 and stained with toluidine blue. A similar staining is obtained for the control (left) and the IONF@CuS condition (right), indicating the abundance of proteoglycans in both conditions.

287 maturation (day 3 ), both in the presence and in the absence of 288 the IONF core (Figure 6, panels A-D). At this stage, some 289 lysosomes still contain intact NPs, while others hold 290 nanostructures resembling the initial nanoassemblies but 291 disassembled into smaller units, with the IONF core also 292 dismantled in the case of IONF@CuS (Figure 6C and D). 293 Additional TEM images are shown in Figure S9 and Figure 294 S10. After 21 days (Figure 6, panels E-L) absolutely no intact 295 assemblies can be detected within the cells anymore. By 296 contrast, neo-formed nanostructures can be clearly seen in 297 lysosomes, generally leaned against the internal side of the 298 membrane, in a "hair-like" manner. Similar additional images (day 9 and day 21) are shown in Figure S11 and Figure S12. 299 Importantly, energy-dispersive X-ray spectroscopy (XEDS) 300 elemental analysis of the transformed nanostructures at day 21301 confirmed the presence of copper along the membrane of 302 lysosomes (Figure S13). Interestingly, only for the IONF@303 $\mathrm{CuS}$ condition could we also detect small 5-7 nm NPs, that 304 we identify as iron deposits in 5-7 nm ferritins previously 305 observed after degradation of iron oxide nanoparticles. ${ }^{23,30,31} 306$ In summary, both $\mathrm{CuS}$ and IONF@CuS nanoassemblies 307 undergo a profound morphological reshaping inside the 308 lysosomes, which occurs in close association to the inner 309 side of the lysosomal membrane, for the $\mathrm{Cu}$ processing. 

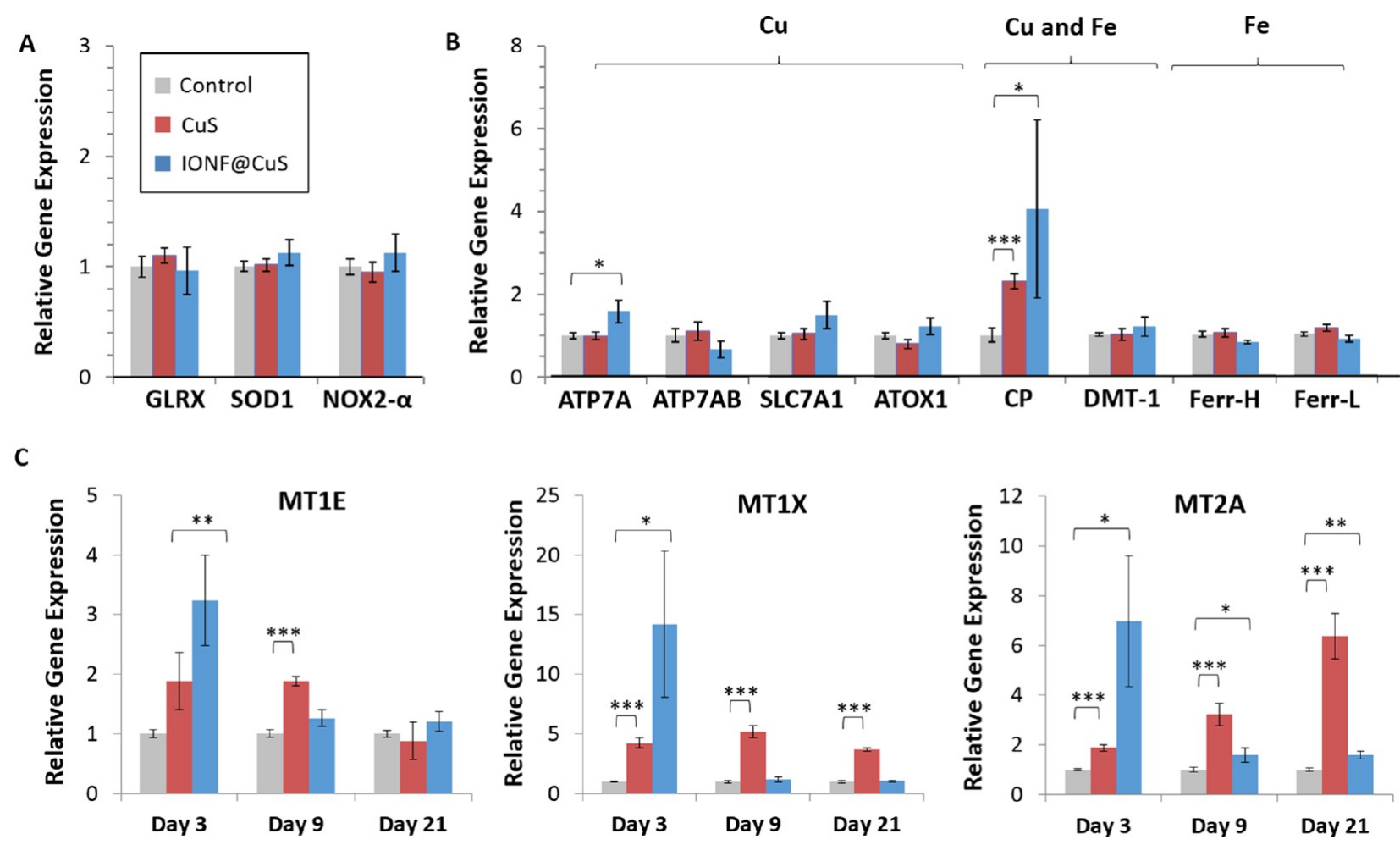

Figure 5. Impact of the internalization of CuS or IONF@CuS on the expression of genes involved in (A) oxidative stress (day 9), (B) copper and iron metabolism (day 9), and (C-E) metallothioneins (MT1E, C; MT1X, D; MT2A, E). Gene expression was normalized to RPLP0 mRNA and expressed relative to the average values of nonlabeled spheroids harvested the same day (control). Significance is indicated as follows: $* p<0.05, * * p<0.01$, and $* * * p<0.001$.

311 Finally, it is important to emphasize that the in vivo 312 complexity is only partially reproduced at the cell culture level. 313 We therefore included an in vivo exploration of the IONF@ $314 \mathrm{CuS} \mathrm{NPs}$ fate at the organism level by injecting them 315 intravenously in mice, harvesting the liver 1 day after the 316 injection or 22 days later and postprocessing it for TEM 317 imaging. The corresponding images, shown in Figure S14, 318 evidence very similar structures to the ones observed at the 319 cellular level.

320 Photothermal Potential of the Biotransformed NPs.

321 The spheroids containing intact NPs (day 1) and processed 322 ones (from day 3 to day 21) were exposed to a NIR laser 323 (Figure 7). Overall, seven independent incubation conditions 324 were tested, corresponding to three and four different 325 extracellular doses for IONF@CuS and CuS NPs, respectively. 326 Each time point corresponds to spheroids $(n=6)$ that have 327 been fixed after $1,3,9$, or 21 days of maturation. Unexpectedly, 328 the photothermal heating efficiency was globally kept constant 329 during the course of spheroid maturation for all the tested 330 doses. Figure $7 \mathrm{~A}$ and $\mathrm{D}$ show representative IR images of the 331 heating at the first (day 1) and last (day 21) time point. A 332 complete IR panel including also images at day 3 and day 9 can 333 be found in Figure S15. Figure 7B and E present the average 334 temperature increases $\Delta T$ over time. All data point out the 335 stability of the photothermal potential of the CuS-based 336 nanoassemblies. For all conditions, the quantity of copper (and 337 iron) within the spheroids remains unchanged over time 338 (Figure 7C and F), direct proof that the spheroids generally do 339 not lose labeled cells nor eject nanomaterials or copper ions. $340 \mathrm{We}$ also tested the photothermal potential of $\mathrm{CuS} \mathrm{NPs}$ 341 dispersed in culture medium at $37^{\circ} \mathrm{C}$, without cells, for 7 days. 342 Results are shown in Figure S16 for different concentrations, clearly demonstrating a significant reduction of the photo- 343 thermal efficiency, over 30\%, in 1 week of incubation. 344

Overall, it appears that despite the massive intracellular 345 structural modification of the CuS and IONF@CuS NPs over 346 weeks in stem cells, their heating potential is exceptionally 347 conserved throughout the analysis period, in a consistent 348 manner at all doses tested.

Magnetometry and X-ray Absorption Spectroscopy 350 at the Spheroid Level Reveal Degradation of the 351 Magnetic Core but No Change in Cu Chemical State. 352 Magnetometry was performed on the IONF@CuS spheroids, 353 to quantitatively detect the magnetic signature of the IONF 354 magnetic core inside the cells over time, as an indicator of its 355 integrity. As shown in Figure 8A (single spheroid magnet- $356 \mathrm{f} 8$ ization curves at room temperature) and Figure $8 \mathrm{~B}$ (average of 357 spheroid saturation magnetization), a sharp reduction of the 358 magnetization is already experienced 1 day after IONF@CuS 359 internalization. The magnetic signal then remains very low 360 from day 3 to day 21, demonstrating that the magnetic core is 361 totally degraded.

X-ray absorption spectroscopy (XAS) of the spheroids at the 363 Fe K-edge in the X-ray absorption near-edge structure regime 364 (XANES) (Figure 8C) confirmed the degradation of the IONF 365 magnetic core upon cellular uptake. Right after internalization 366 in cells, IONFs were identified as maghemite by spectrum 367 comparison with iron oxide references. Besides, the spectrum 368 matches perfectly the one obtained before internalization, for 369 IONFs dispersed in water (see also Figure S17A). By contrast, 370 after 21 days, although the $\mathrm{Fe}$ ions remained in the +3 371 oxidation state, the spectra obtained evolve to a ferrihydrite- 372 like structure and could be modeled with a high content of 373 ferrihydrite (80\%) over maghemite (Figure S17B). It confirms 374 


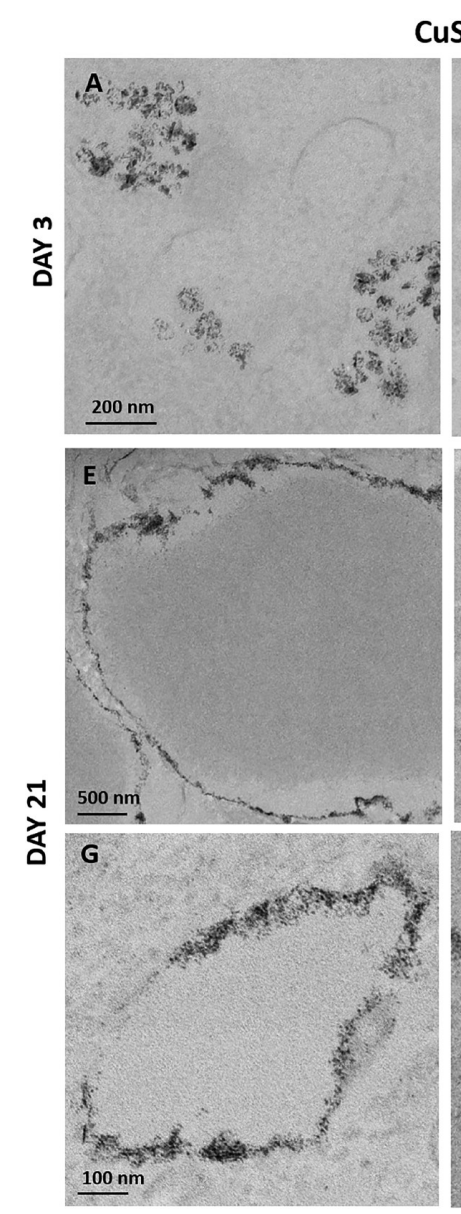

\section{CuS}
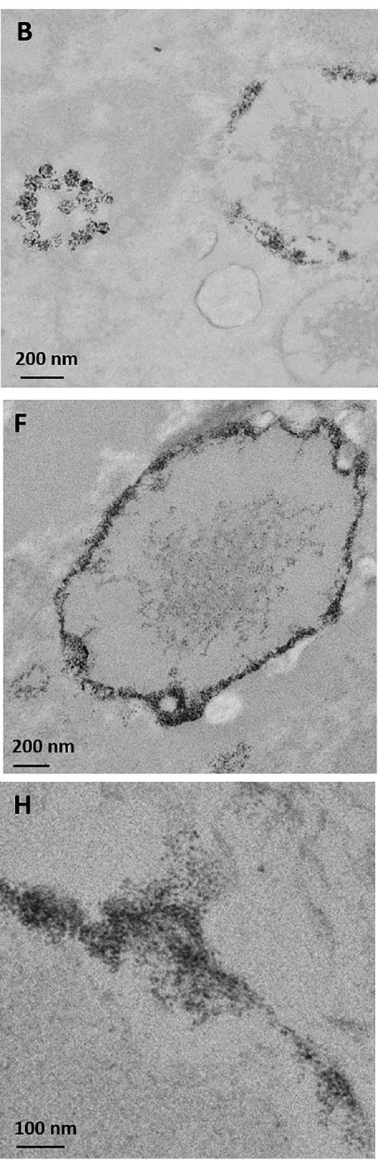

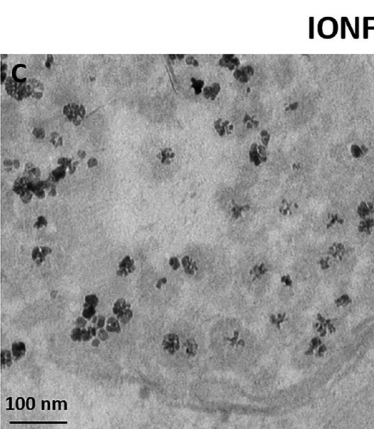

IONF@CuS

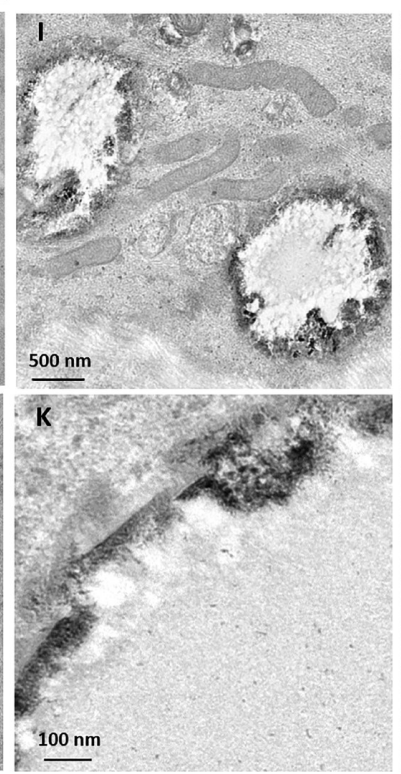

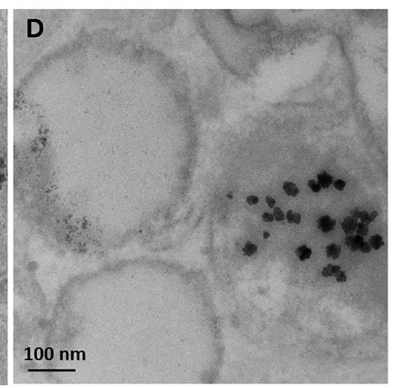

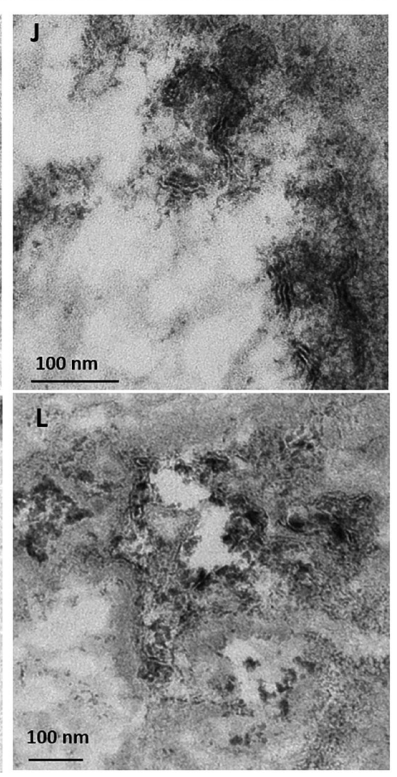

Figure 6. TEM study of the intracellular structural transformation of nanoassemblies over time. Representative TEM images at day 3 for CuS (A, B) and IONF@CuS assemblies (C, D) show the presence of both still intact nanoassemblies and their much smaller degradation products. At day 21 of spheroid maturation, no original nanoassemblies are visible for both $\mathrm{CuS}(\mathrm{E}-\mathrm{H})$ and IONF@CuS (I-L), while the lysosome inner membrane appears decorated with nanomaterial deposits, reshaped in smaller "hair-like" structures.

375 that the degradation products issued from the magnetic core 376 are stored within the ferritin protein as ferrihydrite, as already 377 reported for the degradation of magnetic NPs alone. ${ }^{30,31}$ By 378 contrast, XANES analysis of the spheroids at the $\mathrm{Cu}$ K-edge 379 (Figure 8D) demonstrates no change for the chemical phase 380 and environment of $\mathrm{Cu}$ over time. Moreover, the XANES 381 spectrum of IONF@CuS NPs dispersed in water displays 382 identical edge positions and spectral features to those obtained 383 in cell spheroids at all maturation durations. A fit using $\mathrm{Cu}$ 384 based reference compounds yielded a composition of mainly $385 \mathrm{CuS}$ phase (Figure S17C and D). This is in total agreement 386 with the preservation of the photothermal potential and 387 provides the unequivocal evidence of the massive intracellular 388 transformation of the nanoassemblies into $\mathrm{CuS}$ biologically 389 reshaped materials with the same structural chemistry and, 390 thus, physical photothermal properties.

\section{Maintenance of the Therapeutic Programmed Tasks}

392 in a Cancer Model. The stem cell spheroids, made of primary 393 human mesenchymal stem cells, were used as a model to 394 enable a long-term study of the intracellular remodeling of the $395 \mathrm{CuS}$ NPs, as well as to evaluate the biological impact of the 396 NPs on healthy cells. Nevertheless, the photothermal property 397 of $\mathrm{CuS}$ is usually used to treat diseases, for example, to kill 398 tumor cells. Within the spheroids, the stem cells stop dividing 399 and create a rich extracellular matrix, which allows them to be 400 kept viable over months; by contrast, highly proliferating cancer cells are more challenging to culture in 3D culture in 401 the long-term. Yet, we managed to transfer the stem cell 402 spheroid model to glioblastoma cancer cells, which successfully 403 formed 3D spheroids of similar size and number of cells and 404 were maintained viable over 9 days (Figure 9A). Two doses of 405 f9 $\mathrm{CuS}$ NPs were investigated, corresponding to 0.5 and $0.9 \mathrm{pg}$ of 406 $\mathrm{Cu}$ per cell, in the same range as what was obtained in stem 407 cells. The intracellular heating performances of the CuS NPs 408 were maintained over the 9 days, with heat measurements 409 performed at days 1, 3, 6, and 9. This is evidenced in Figure 410 9B, C, and D, showing typical IR images of single spheroid 411 heating, typical temperature elevation curves for each dose and 412 each measurement day, and a temperature increase (at plateau) 413 averaged over five independent spheroids, as a function of 414 time. Importantly, these series of measures were achieved 415 starting from $37^{\circ} \mathrm{C}$, with laser exposure at low power density 416 $\left(0.3 \mathrm{~W} / \mathrm{cm}^{2}\right)$, totally approved for clinical use, and for $10 \mathrm{~min}, 417$ a duration typically used for photothermal cancer therapy. 418 With these settings, the preservation of the heat generation 419 over time perfectly translated into a conserved therapeutic 420 efficacy, as spheroid viability after laser exposure at days 1, 3, 6, 421 and 9 was systematically decreased to $60 \%$ and $30 \%$ compared 422 to the nonexposed control spheroids, for 0.5 and $0.8 \mathrm{pg}$ of $\mathrm{Cu} 423$ per cell, respectively.

Hypothetical Mechanism. The data presented here 425 provide insights into the landscape of intracellular reshaping 426 

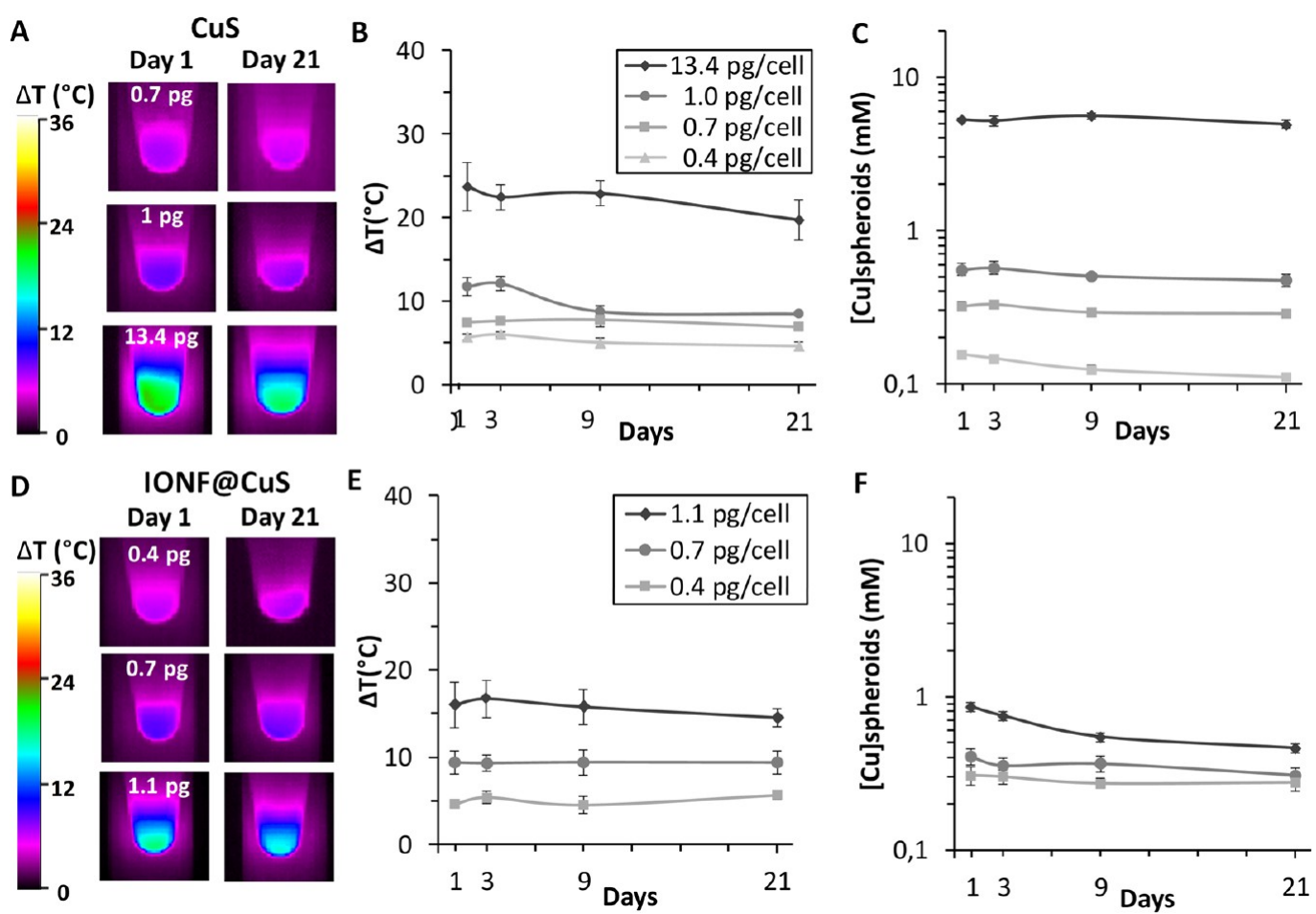

Figure 7. Laser-induced photometric study on CuS and IONF@CuS NP-containing spheroids over time. A and D show typical IR images of three concentrations of CuS- and IONF@CuS-treated spheroids, respectively, at day 1 and 21 of spheroid maturation. Images were taken after $5 \mathrm{~min}$ of $1064 \mathrm{~nm}$ laser irradiation at $0.3 \mathrm{~W} \mathrm{~cm}^{-2}$ (heating plateau achieved at 1-2 min of laser application). B and E present the average time plots of the heating efficiencies for all incorporated doses for spheroids treated with CuS (B) and IONF@CuS (E) at days 1, 3, 9, and 21 of spheroid maturation. $\mathrm{C}$ and F present $[\mathrm{Cu}]$ measurements obtained by ICP of the $10 \mu \mathrm{L}$ solution containing the individual CuS(C) and IONF@CuS-containing (F) spheroids.

427 of functional nanomaterials, with the evidence that a 428 nanoparticle can be significantly bioprocessed and transformed 429 into different shapes and sizes while maintaining its photo430 thermal function. This behavior was observed only for copper 431 sulfide material, while magnetic cores were already processed 432 to nonmagnetic after a few days as demonstrated by magnetic 433 measurements and XAS. Such differences in cell bioprocessing 434 of both materials may have different origins including the low 435 solubility of metal sulfides compared to metal oxides, the 436 differences in size and shape, but also the differences in cellular 437 management of both metal ions, where $\mathrm{Fe}$ is typically 438 metabolized rapidly after cellular uptake. ${ }^{44}$ Naturally, Fe is 439 transported from the outside of the cell to the inside by 440 transferrin, which, after binding to the transferrin receptor, 441 ends up in endosomes/lysosomes compartments. The receptor 442 can recycle back to the cell membrane, where the Fe ion can 443 bind small molecules such as citrate that will aid in its 444 solubilization and transport it out of the endosomes into the 445 labile iron pool of the cell. ${ }^{45}$ For Fe brought inside the cells via $446 \mathrm{NPs}$, it is generally the same pathway, where the NPs 447 sequestered in endosomes are gradually degraded and free $448 \mathrm{Fe}$ ions are transported out of the endosomes into the 449 cytoplasm. $^{46}$ For copper, the process is different and less 450 understood. Naturally, $\mathrm{Cu}$ enters the cells mainly via the 451 copper transporter 1 (CTR1) and is immediately linked to one 452 of its chaperones, such as copper chaperone for SOD (CCS) or $453 \mathrm{Sco1}$, an enzyme involved in the synthesis of cytochrome $c$ 454 oxidase. ${ }^{47} \mathrm{Cu}$ can be stored at low levels in metallothioneins, 455 but overall, transport of $\mathrm{Cu}$ ions from endo- and lysosomes 456 toward the cytoplasm is very limited, as it does not occur 457 naturally. For $\mathrm{Cu}$-containing NPs, this poses an entirely different scenario, in which the cells are not equipped to deal 458 with excess levels of $\mathrm{Cu}$ ions in their endosomal compartments. 459 $\mathrm{CuO}$ NPs, which typically dissolve quite quickly, result in free 460 $\mathrm{Cu}$ ions already present in the cell medium and cellular uptake 461 of excess $\mathrm{Cu}$ ions that can lead to cell death. ${ }^{48}$ Alternatively, 462 the low solubility of $\mathrm{CuS}$ and the small contact time during 463 incubation allowed the internalization of the CuS-based 464 nanostructures, still intact, in the endosomes of the cells, on 465 the first day.

466

Moreover, TEM observation of these $\mathrm{CuS}$ confirmed their 467 porous and polycrystalline architecture, made of tiny particles 468 $7-11 \mathrm{~nm}$ in diameter. Such tiny crystals are organized in a 469 hollow porous morphology resulting from the Kirkindall effect 470 in the presence of polyvinylpyrrolidone (PVP). The degrada- 471 tion of similar hollow CuS NPs in different physiological 472 buffers including PBS, RMPI, and DMEM was investigated by 473 Ortiz de la Solorzano et al. ${ }^{41}$ at $37{ }^{\circ} \mathrm{C}$, who showed their 474 dissolution into water-soluble sulfate-based copper species. 475 This dissolution led to the decrease of the NIR absorption 476 peak with almost a total disappearance after 13 days. 477 Consequently, it is expected that the disappearance of the 478 NIR absorption should lead to a loss of the photothermal 479 properties, which was not observed in our investigation for 480 both types of nanoparticles in cells. These results are in good 481 agreement with XAS data and indicate that the degradation of 482 $\mathrm{CuS}$ in the endosomes by dissolution of water-soluble copper 483 species is not the predominant mechanism, at least on the scale 484 of 29 days. At day 3, in addition to intact hollow structures, 485 smaller $\mathrm{CuS}$ units are also observed by TEM, and these units 486 decorate the internal membrane of the endosomes. Interest- 487 ingly, despite the presence of such dissociated structures, no 488 

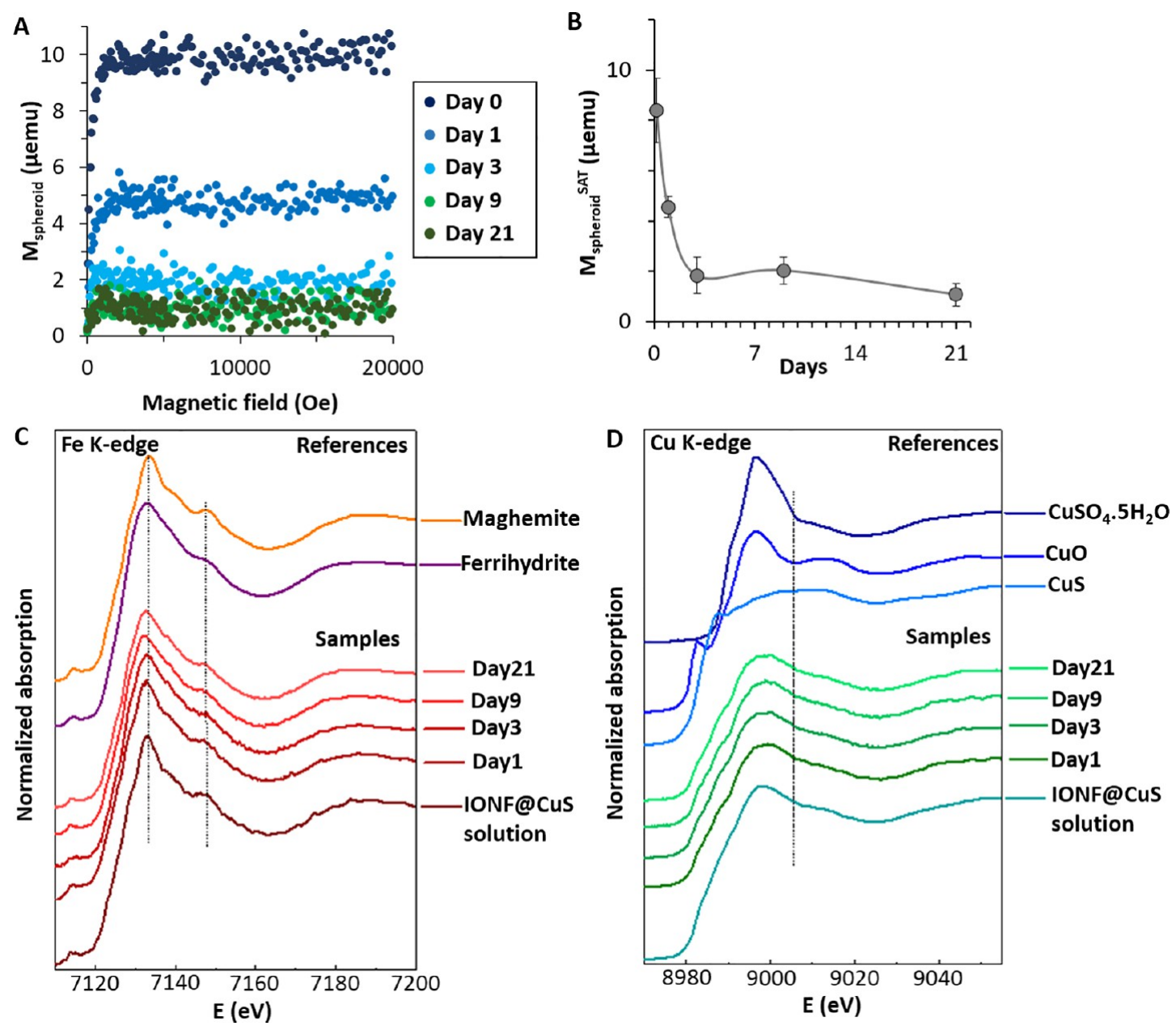

Figure 8. Structural characterization of IONF@CuS NPs processed by the spheroids from incubation day (day 0 ) to 3 weeks of maturation (day 21), taking advantage of the magnetic core as an additional integrity tracer. (A) Typical magnetometry curves for single spheroids at room temperature over time. (B) Magnetization at saturation averaged over four independent spheroids at each time point (total of 20 spheroids analyzed). (C) XANES spectra at the Fe K-edge of iron oxide references $\left(\gamma\right.$ - $\mathrm{Fe}_{2} \mathrm{O}_{3}$ (maghemite) and $\mathrm{Fe}_{2} \mathrm{O}_{3} \cdot 0.5 \mathrm{H}_{2} \mathrm{O}$ (ferrihydrite)), IONF@CuS NPs incubated from day 1 to day 21, and IONF@CuS NPs dispersed in water. (D) XANES spectra at the Cu K-edge of copperbased compound references $\left(\mathrm{CuSO}_{4} \cdot 5 \mathrm{H}_{2} \mathrm{O}, \mathrm{CuO}, \mathrm{CuS}\right), \mathrm{IONF} @ \mathrm{CuS}$ nanoassemblies incubated from day 1 to day 21 , and IONF@CuS NPs dispersed in water.

489 change in photothermia or chemical phase was observed. 490 Consequently, we attributed the formation of such free units to 491 the disassembly (by dissolution of PVP) of the tiny 492 nanoparticles from the shell of $\mathrm{CuS}$. After coating with 493 positively charged endosomal proteins they undergo inter494 action and accumulation at the negatively charged lysosomal 495 inner membrane. A comparable disintegration mechanism has 496 been observed in vivo in blood plasma for similar hollow shells 497 by Guo et al. ${ }^{40}$ At day 21, TEM showed that no intact $\mathrm{CuS}$ 498 nanostructures remained for both types of nanostructures, 499 while the lysosome inner membrane appeared decorated with 500 4-8 nm nanoparticles organized in a hair-like structure. Such 501 structures are copper-based, as confirmed by XEDS analysis. 502 Therefore, we may hypothesize that these structures were 503 generated by continuous disintegration of the $\mathrm{CuS}$ over time 504 and reorganization of the tiny subunits released.

505 At high concentrations, the nanohybrids induced mitochon506 drial stress but no ROS generation, while $\mathrm{Cu}$-based nano507 particles are typically associated with the induction of 508 ROS. $^{36,49}$ The lack of mitochondrial ROS also reflects a low 509 level of dissolution of $\mathrm{CuS}$. However, the observed 510 mitochondrial stress and the increasing activity of genes related to copper suggest that free copper species are released 511 during the bioprocessing of the nanostructures. Indeed, XAS 512 analysis shows that the $\mathrm{CuS}$ shell is composed of a mixture of 513 $\mathrm{CuS}$ and $\mathrm{CuO}$ phases and free $\mathrm{CuSO}_{4} \cdot 5 \mathrm{H}_{2} \mathrm{O}$. Given the higher 514 solubility of $\mathrm{CuO}$ compared to $\mathrm{CuS}$ also established in cells, we 515 may hypothesize that, upon the nanomaterial bioprocessing, 516 free $\mathrm{CuO}$ species are released upon the nanomaterial 517 bioprocessing and that they are stored in the copper-related 518 proteins.

519

Concerning the stability of photothermal potential upon the 520 degradation of the CuS-based NPs into small structures, it is 521 difficult to establish a clear reason, as the origins of absorption 522 in copper sulfide remain poorly understood and are still a 523 subject of debate. While some associate this NIR absorption to 524 $\mathrm{d}-\mathrm{d}$ transition of $\mathrm{Cu}^{2+}$ ions, which is not affected by the 525 solvent or the surrounding environment, others attribute such 526 a behavior to a plasmonic effect generated by free hole 527 oscillations. $^{37,38}$ In this case the effect of morphology on the 528 localized surface plasmon resonance is not clearly understood, 529 and it seems that the morphology has less influence on their 530 plasmon oscillation mode with respect to the composition. ${ }^{38}$ In 531 all cases we can attribute the conservation of the photothermal 532 
A

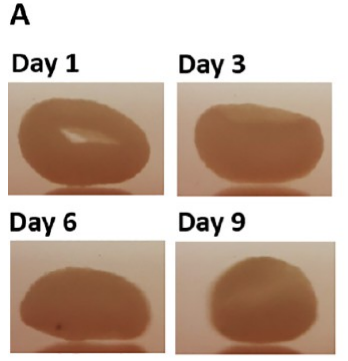

B

D

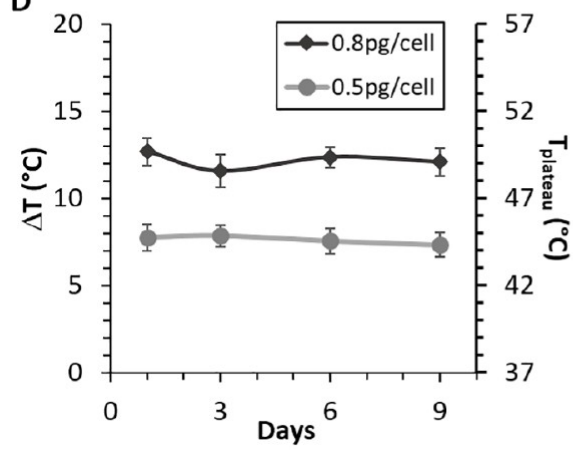

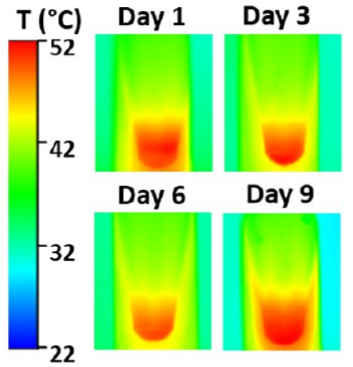

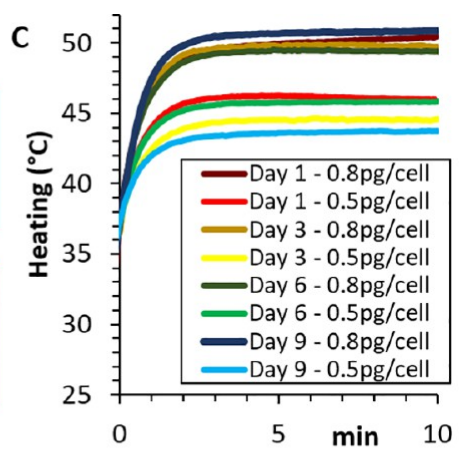

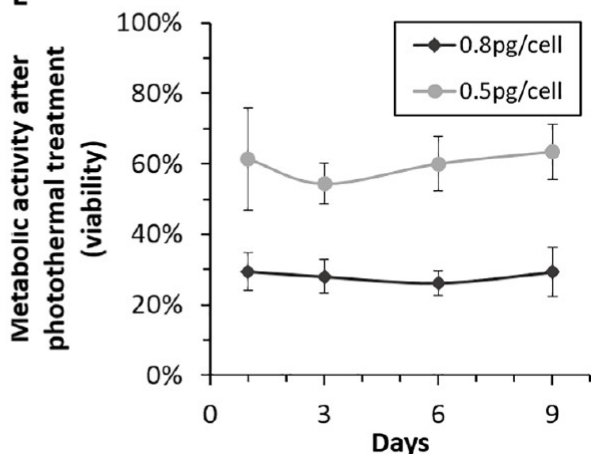

Figure 9. Preservation of photothermia and subsequent therapeutic potential in a glioblastoma spheroid model. (A) Representative photographs of single spheroids made of $2.5 \times 10^{5}$ cancer cells containing CuS NPs at a dose of 0.8 pg of Cu per cell, at days $1,3,6$, and 9. (B) Typical IR images of cancer spheroids (loaded with $\mathrm{CuS}$ NPs at $0.8 \mathrm{pg}$ of $\mathrm{Cu}$ per cell) in a $0.5 \mathrm{~mL}$ tube $(10 \mu \mathrm{L}$ volume), at days $1,3,6$, and 9 of spheroid maturation, upon $10 \mathrm{~min}$ of laser irradiation at $0.3 \mathrm{~W} \mathrm{~cm}^{-2}$. (C) Typical heating curve for single spheroids, at each day (1, 3,6 , and 9) and for the two doses ( 0.5 and $0.8 \mathrm{pg}$ of $\mathrm{Cu}$ per cell). (D) Plateau temperature, expressed as temperature elevation (left vertical axis) and absolute temperature (right secondary axis), averaged over five independent spheroids, as a function of time. (E) Metabolic activity (Alamar blue assay) of the spheroids $(n=5$ per day and per dose), measured $24 \mathrm{~h}$ after photothermal treatment, expressed in $\%$ compared to nontreated control spheroids $(n=5$ per day and per dose).

533 potential to the preservation of the chemical composition, as 534 confirmed by XAS performed over days on the units formed 535 after disintegration of the original $\mathrm{CuS}$ nanomaterials.

536 These results show clearly that multifunctional materials 537 with predefined properties can be bioprocessed by cells into 538 new reshaped biological forms, which may present a high 539 biocompatibility while maintaining their functionalities and 540 their programmed therapeutic tasks.

\section{${ }_{541}$ CONCLUSION}

542 Herein, we studied the effect that a long intracellular exposure 543 of CuS-based nanomaterials could have on both their own 544 physical functionalities and on the biology of the stem cells 545 exposed. $\mathrm{CuS}$ were produced as nanoassemblies, without $546(\mathrm{CuS})$ and with a magnetic core (IONF@CuS), internalized in 547 stem cells further assembled in spheroids to allow long-term 548 3D culture. Overall, the CuS and IONF@CuS NPs did not 549 trigger an adverse biological response either immediately (over 550 the cell viability, oxidative stress), or in the longer-term (over 551 stem cell differentiation, oxidative stress, iron and copper 552 metabolism). However, the nanoassemblies were massively 553 transformed inside the endosomes of the cells, with only few 554 intact structures observed already after 3 days of cellular 555 processing. These transformations were quantitatively con556 firmed by magnetometry by the disappearance of the spheroid 557 magnetism initially provided by the IONF core and confirmed 558 by XAS synchrotron measurements, revealing the trans559 formation of maghemite into ferrihydrite over time. The 560 magnetic core was, thus, totally degraded by the cells and stored within the ferritin protein, as generally observed for 561 magnetic NPs alone. This magnetic degradation reflects the 562 disassembling of the hybrid IONF@CuS structure, making it 563 possible for the lysosomal harsh environment to access the 564 core and degrade it. However, the loss of magnetism was not 565 associated with a comparable loss of the photothermal 566 potential of the spheroids over time, provided by the $\mathrm{CuS} 567$ physicochemical structure of the metal chalcogenide semi- 568 conductor. The demonstration by XAS that the copper 569 chemical phase remained the same during the whole 3 weeks 570 of the spheroid maturation period further confirmed their 571 functional stability. The copper sulfide nanoassemblies were 572 therefore reshaped by the cells, triggering a process of nontoxic 573 metabolization in which the cellular environment managed to 574 transform the materials into smaller and stable structures with 575 the same high photothermal potential. Since these nano- 576 particles are devoted to therapeutic applications, the photo- 577 thermal follow-up was also performed on spheroids made of 578 cancer cells. The photothermal potential and its related 579 therapeutic function were maintained all through the cancer 580 spheroid maturation (over 9 days). In order to implement 581 efficient theranostic applications, it appears pivotal to study the 582 balance between biocompatibility, degradation, and biopro- 583 cessing while maintaining their physical properties. Herein, we 584 demonstrate that a theranostics nanomaterial can undergo a 585 severe clear cell-mediated breakdown but still maintain its 586 programmed tasks after intracellular processing. 


\section{MATERIALS AND METHODS}

589 Materials. All reagents were of analytical purity and used without 590 further purification. Iron(II) chloride tetrahydrate $\left(\mathrm{FeCl}_{2} \cdot 4 \mathrm{H}_{2} \mathrm{O}\right.$, $59199 \%)$, sodium hydroxide $(\mathrm{NaOH}, 99.99 \%)$, diethylene glycol (DEG, $59299 \%), \mathrm{N}$-methyldiethanolamine (NMDEA, 99\%), nitric acid $\left(\mathrm{HNO}_{3}\right.$, $59370 \%)$, copper(II) nitrate hemi(pentahydrate) $\left(\mathrm{Cu}\left(\mathrm{NO}_{3}\right)_{2} \cdot 2.5 \mathrm{H}_{2} \mathrm{O}\right.$, $594 \geq 99.99 \%$ ), polyvinylpyrrolidone ( $\mathrm{PVP}, M_{\mathrm{w}} 55 \mathrm{kDa}$ ), poly(ethylene 595 glycol) methyl ether thiol (PEG-SH, $M_{\mathrm{w}} 2 \mathrm{kDa}$ ) hydrazine hydrate $596(55 \%)$, ammonium sulfide solution $\left(\left(\mathrm{NH}_{4}\right)_{2} \mathrm{~S}, 20 \%\right)$, sodium 597 cacodylatetrihydrate $(\geq 98 \%)$, glutaraldehyde solution $(25 \%$ in $598 \mathrm{H}_{2} \mathrm{O}$ ), and formalin solution $(10 \%)$ were purchased from Sigma599 Aldrich (France). Iron(III) chloride hexahydrate $\left(\mathrm{FeCl}_{3} \cdot 6 \mathrm{H}_{2} \mathrm{O}, 99 \%\right)$ 600 and ethanol were obtained from VWR (France). Live-Dead Green 601 dead cell and MitoTracker Red CMXRos were purchased from Life 602 Technologies (Thermo Fisher, Belgium).

603 Iron Oxide Nanoflower Core. IONFs were synthesized using a 604 modified polyol synthesis as previously described. ${ }^{50}$ In brief, the iron 605 precursors were solubilized in a DEG and NMDEA mixture $(1: 1 \mathrm{v} / \mathrm{v})$ 606 and heated to $220{ }^{\circ} \mathrm{C}$ for $2.5 \mathrm{~h}$ to obtain the alkaline hydrolysis. The 607 obtained magnetic nanoflowers were cleaned with ethanol and ethyl 608 acetate and treated with $10 \%$ nitric acid to complete the oxidation. 609 They were then redispersed in water and mixed with 0.3\% PVP (55 $610 \mathrm{kDa}$ ) prior to the following step.

611 Copper Sulfide Assembly. The synthesis of the substoichio612 metric copper sulfide $\mathrm{Cu}_{2-x} \mathrm{~S}$ assembly has been carried out in the 613 presence or in the absence of an IONF core using a two-step reaction 614 through a template sacrificial synthesis method, modified from ref 33. 615 In the first step, $10 \mathrm{mg}$ of cupric nitrate, $\mathrm{Cu}\left(\mathrm{NO}_{3}\right)_{2}$, was dissolved in $61630 \mathrm{~mL}$ of Milli-Q $\mathrm{H}_{2} \mathrm{O}$ and mixed with $0.3 \mathrm{~g}$ of PVP $(55 \mathrm{kDa})$ and 617 IONF (if present) at $[\mathrm{Fe}]=0.3 \mathrm{mM}$. After $15 \mathrm{~min}$ of shaking at room 618 temperature $100 \mu \mathrm{L}$ of hydrazine $5.5 \%$ was added rapidly in the 619 mixture to induce the formation of $\mathrm{Cu}_{2} \mathrm{O}$ NPs. The obtained product 620 was cleaned by centrifugation at $9000 \mathrm{~g}$ for $45 \mathrm{~min}$ and resuspended in $62130 \mathrm{~mL}$ of Milli- $\mathrm{Q}_{2} \mathrm{O}$. The second step of the reaction consisted in 622 the sulfidation of the $\mathrm{Cu}_{2} \mathrm{O}$ shell previously synthesized using $0.1 \mathrm{M}$ 623 sodium sulfide followed by heating at $50{ }^{\circ} \mathrm{C}$ for $2 \mathrm{~h}$. After several 624 washings by centrifugation and resuspension in Milli- $\mathrm{Q} \mathrm{H}_{2} \mathrm{O}$, the 625 surface of the nanoassemblies was PEGylated by shaking the sample 626 overnight in the presence of PEG-SH (final concentration $10 \mathrm{mg}$ / $627 \mathrm{~mL}$ ) at $4{ }^{\circ} \mathrm{C}$ and subsequent washing by centrifugation. These 628 reactions resulted in the production of copper sulfide nanoassemblies 629 (hollow) or of iron oxide nanoflower-like cores surrounded by copper 630 sulfide nanoassemblies (IONF@CuS) when achieved in the presence 631 of IONF (rattle-like).

632 Morphological and Optical Characterization. TEM images 633 were obtained using a Hitachi HT 7700 TEM operated at $80 \mathrm{kV}$ 634 (Elexience, France), and images were acquired with a charge-coupled 635 device camera (AMT). UV-vis-NIR characterization was performed 636 with a real-time Avaspec-USB2 spectrometer. $\mathrm{Cu}$ and Fe concen637 tration was determined by elemental analysis using ICP-AES (iCAP 638 6500, Thermo Scientific).

639 Laser-Induced Thermometric Measurements. Heating pro640 files of aqueous solutions were obtained by placing $10 \mu \mathrm{L}$ of $\mathrm{CuS}$ or 641 IONF@CuS dispersions at concentrations ranging from 0.5 to $40 \mathrm{mM}$ 642 of $\mathrm{Cu}$ in a $0.5 \mathrm{~mL}$ tube at a $4 \mathrm{~cm}$ distance from the laser source. The 643 samples were irradiated with a $1064 \mathrm{~nm}$ laser at a power density of 0.3 $644 \mathrm{~W} \mathrm{~cm}^{-2}$ until equilibrium temperature was reached (typically in 1-2 $645 \mathrm{~min}$, measurements were performed over $5 \mathrm{~min}$ to be sure to measure 646 the plateau temperature). The increase in temperature was measured 647 using an FLIR SC7000 infrared thermal camera. The spheroids were 648 analyzed in the same configuration. All values are reported as means 649 of at least three separate experiments.

650 Cell Culture and Nanoparticle Uptake. Human mesenchymal 651 stem cells were purchased from Lonza and were cultured in hMSC652 basal medium at $37{ }^{\circ} \mathrm{C}, 5 \% \mathrm{CO}_{2}$, and $95 \%$ relative humidity. Human 653 glioblastoma cells U87 were purchased from ATCC and cultured in 654 DMEM medium supplemented with $1 \%(\mathrm{w} / \mathrm{v})$ streptomycin, $1 \%(\mathrm{w} /$ $655 \mathrm{v})$ penicillin, and $10 \%(\mathrm{w} / \mathrm{v})$ FBS. At $90 \%$ confluence, cells were 656 incubated with the nanoassemblies diluted in serum-free RPMI medium. The copper concentration in the medium ranged from 0.1 to 657 $1 \mathrm{mM}$. After $4 \mathrm{~h}$ of incubation, the medium was removed and the cells 658 were rinsed and incubated further for $2 \mathrm{~h}$ in complete hMSC-basal 659 medium to remove any noninternalized copper nanoassemblies. Then, 660 cells were detached by trypsinization, counted, and immediately 661 analyzed or further processed. To assess the intracellular NP content, 662 $2.5 \times 10^{5}$ cells were digested in pure nitric acid for $48 \mathrm{~h}$ until total 663 dissolution, diluted up to $2 \% \mathrm{HNO}_{3}$ in ultrapure $\mathrm{H}_{2} \mathrm{O}$, and analyzed 664 by elemental analysis. 665

Nanotoxicity Study. For the biocompatibility assays, $1.25 \times 10^{3} 666$ or $2.5 \times 10^{3}$ cells per well were seeded in 96-multiwell culture plates 667 at $100 \mu \mathrm{L}$ total volume and incubated overnight. IONF@CuS or CuS 668 nanoassemblies at the concentrations of $0.04,0.16,0.32,1.6$, and 3.2669 $\mathrm{mM}$ of $\mathrm{Cu}$ were dispersed in cell culture media and incubated with 670 hMSC cells for $24 \mathrm{~h}\left(2.5 \times 10^{3}\right.$ cells $)$ or $72 \mathrm{~h}\left(1.25 \times 10^{3}\right.$ cells $)$. At 671 the end of the incubation, the media was removed and fresh media 672 was provided containing Live-Dead Green dead cell and 673 MitoTracker Red CMXRos (Molecular Probes, Life Technologies 674 Europe, BV, Belgium), after which the cells were further incubated for 675 $30 \mathrm{~min}$ in a humidified atmosphere at $37{ }^{\circ} \mathrm{C}$ and $5 \% \mathrm{CO}_{2}$. Next, the 676 cells were washed three times with PBS, fixed with $4 \% 677$ paraformaldehyde (PFA), and counterstained with Hoechst 33342678 nuclear stain solution (Life Technologies, Belgium). Next, the plates 679 were analyzed using the INCell Analyzer 2000 (GE Healthcare Life 680 Sciences, Belgium), while 2000 cells per condition were acquired in 681 triplicates using a $20 \times$ objective lens for the DAPI/DAPI (Hoechst), 682 FITC/FITC (Live-Dead Green), and TexasRed/TexasRed (Mito- 683 Tracker Red CMXRos) channels. The acquired images were 684 processed using the InCell Investigator software (GE Healthcare 685 Life Sciences, Belgium). Cell viability was calculated by segmenting 686 cell nuclei and dead cells (signal crossing the threshold in the green 687 channel overlapping with the nuclei) using the IncCell Developer 688 software (GE Healthcare Life Sciences, Belgium). The number of live 689 cells per each condition was calculated as the total number of nuclei 690 counted minus the number of dead cells. The values were then 691 normalized by the control conditions $(=100 \%)$. Finally, for 692 mitochondrial stress, the total area of cellular mitochondria was 693 used, while for mitochondrial ROS, the intensity of the mitochondrial 694 stain was determined. The respective channel was segmented using 695 the Hoechst images as seed, and the total size and intensity of the 696 mitochondrial network were determined for each individual cell. 697 These values were than normalized by the respective control 698 conditions $(=100 \%)$. Results represent quantitative data for the 699 analysis of a minimum of 2000 cells per condition. Values are 700 presented as mean + SEM $(n=3)$.

Stem Cell Spheroid Formation and Characterization. A total 702 of $2.5 \times 10^{5}$ stem cells were centrifuged ( $1200 \mathrm{rpm}$ for $5 \mathrm{~min}$ ) in 15703 $\mathrm{mL}$ tubes to form a pellet and cultured in order to induce cell 704 differentiation (chondrogenesis). The cells then spontaneously 705 formed a spheroid, which could be kept in culture for months 706 (here up to 3 weeks of spheroid maturation). The differentiation 707 medium was composed of high-glucose DMEM supplemented with 708 $1 \%$ penicillin-streptomycin, $0.1 \mu \mathrm{M}$ dexamethasone, $1 \mathrm{mM}$ sodium 709 pyruvate, $50 \mu \mathrm{M}$ L-ascorbic acid 2-phosphate, $0.35 \mathrm{mM}$ L-proline 710 (Sigma), 1\% ITS-Premix (Corning), and $10 \mathrm{ng} / \mathrm{mL}$ TGF- $\beta 3711$ (Interchim) and was changed twice a week. For histological analysis, 712 spheroids harvested after 21 days of maturation were fixed overnight 713 in $10 \%$ formalin, before paraffin inclusion and cutting. Slices that were 714 $4 \mu \mathrm{m}$ thick were treated with toluidine blue $0.04 \%$ for collagen 715 staining and then analyzed by optical microscopy.

At days 1, 3, 9, and 21, the spheroids were fixed with 4\% PFA for 2717 $\mathrm{h}$ at room temperature and transferred in PBS for photothermal 718 analysis, magnetic characterization, and elemental characterization. 719 For the electron microscopy analysis, other spheroids at the same time 720 points were fixed with $2 \%$ glutaraldehyde in $0.1 \mathrm{M}$ cacodylate buffer 721 for $2 \mathrm{~h}$, contrasted with oolong tea extract (OTE) $0.5 \%$ in $0.1 \mathrm{M} \mathrm{Na} 722$ cacodylate buffer, postfixed with $1 \%$ osmium tetroxide containing 723 $1.5 \%$ potassium cyanoferrate, gradually dehydrated in ethanol (30\% to 724 $100 \%)$, and gradually embedded in epoxy resins. Ultrathin slices (70 725 
$726 \mathrm{~nm}$ ) were collected onto 200 mesh copper grids and counterstained 727 with lead citrate prior to being observed by TEM.

728 Gene Expression Quantification by qPCR. Total RNA was 729 extracted from spheroids at different maturation times using a 730 NucleoSpin RNA II kit (Macheney-Nagel). Reverse transcription into $731 \mathrm{cDNA}$ was achieved using SuperScript II reverse transcriptase 732 (Invitrogen) with random hexamers as primers according to the 733 manufacturer's instructions. qPCR was performed with StepOnePlus 734 (Applied Biosystems) using the SYBR Green reagent (Applied 735 Biosystems). The expression of reference gene RPLP0 was used as a 736 housekeeping transcript gene. Each value is obtained by the average of 737 at least two wells gathering a minimum of three independent 738 repetitions. The sequences of primers used are listed in Table S1.

739 Magnetometry of the Internalized IONF Core by VSM. Cell 740 magnetization right after IONF@CuS nanoassembly incubation and 741 in samples fixed at different spheroid maturation times was measured 742 by magnetometry using a PPMS device equipped with a vibrating 743 sample magnetometer (VSM) option (Quantum Design). The 744 analysis was performed at $300 \mathrm{~K}$, between 0 and $20000 \mathrm{Oe}$, and 745 provides the saturation magnetization of the sample (in emu).

746 XAS/Synchrotron Measurements. XAS measurements were 747 performed on the spheroids pooled in groups of 4 or 5 for each 748 maturation time to increase the signal-to-noise ratio. Measurements 749 were achieved in the XANES regime at the CRG beamline BM25750 SpLine of the European Synchrotron Radiation Facilities (ESRF) in 751 Grenoble (France). The spectra were acquired at the Fe K-edge $752(7112 \mathrm{eV})$ and $\mathrm{Cu}$ K-edge $(8980 \mathrm{eV})$ at room temperature and 753 atmospheric pressure in transmission and fluorescence modes. Metal 754 foils of $\mathrm{Fe}$ and $\mathrm{Cu}$ elements were measured as energy calibration 755 references. Iron oxides (as maghemite and ferrihydrite) and several 756 copper-based materials $(\mathrm{Cu}-\mathrm{S}-\mathrm{O}$ compounds as copper sulfides, 757 copper oxides, and copper sulfates) were chosen as standards. For 758 each condition (at days 1, 3, 9, and 21 of maturation), a group of 3 or 7594 multicellular spheroids was measured to improve the signal-to-noise 760 ratio. XANES spectra of IONF, IONF@CuS, and CuS initial solution 761 samples were also evaluated. Data normalization, energy calibration, 762 and analysis of the XAS data were carried out using the Demeter 763 software package (Athena program). ${ }^{51}$

764 Cancer Cell Spheroid Formation and Photothermal 765 Therapy. In the exact same way as for the stem cells, $2.5 \times 10^{5}$ 766 U87 cancer cells were pelleted and kept in complete culture medium 767 for 9 days. At days 1, 3, 6, and 9, the spheroids (5 per day) were 768 collected and transferred to $0.5 \mathrm{~mL}$ tubes (one spheroid per tube) in $76910 \mu \mathrm{L}$ of culture medium. The tubes were placed in a thermostatic 770 device so that the sample is maintained at a temperature of $37{ }^{\circ} \mathrm{C}$ 771 before exposure to the laser. Heating was achieved with the spheroids 772 placed $4 \mathrm{~cm}$ away from the laser source $(1064 \mathrm{~nm})$, corresponding to 773 a laser power density of $0.3 \mathrm{~W} \mathrm{~cm}^{-2}$.

774 The samples were irradiated for $10 \mathrm{~min}$. The increase in 775 temperature was measured using an FLIR SC7000 infrared thermal 776 camera. After laser treatment, the spheroids were transferred to a 48777 multiwell plate, and each single spheroid's metabolic activity was 778 measured $24 \mathrm{~h}$ later, by the Alamar blue assay, and renormalized by 779 nontreated control spheroid values (5 control spheroids for each 780 measurement day).

781 Statistical Analysis. All values are reported as means and 782 standard error of the mean. Significant differences were determined 783 using Tukey's test in one-way analysis of variance (ANOVA). * 784 denotes a $p$-value $<0.05$ (significant result), $* *$ a $p$-value $<0.01$ (very 785 significant), and $* * *$ a $p$-value $<0.001$ (highly significant).

\section{ASSOCIATED CONTENT}

\section{S1 Supporting Information}

788 The Supporting Information is available free of charge at 789 https://pubs.acs.org/doi/10.1021/acsnano.1c00567.

790 Additional nanoparticle and in vivo TEM images, DLS 791 analysis, light-to-heat conversion coefficient, elemental 792 analysis, InCell analyzer microscopy images, gene 793 expression, STEM-HAADF and XEDS characterization, supplementary IR images, in vitro photothermal analysis, 794 XANES synchrotron spectra, and the qPCR primers list 795 (PDF)

AUTHOR INFORMATION

\section{Corresponding Authors}

798

Ali Abou-Hassan - Sorbonne Université, CNRS UMR234, 799 PHysico-chimie des Electrolytes et Nanosystèmes InterfaciauX, 800 PHENIX, F-75005 Paris, France; Nanobiotecnología (IMDEA-Nanociencia), Unidad Asociada al Centro 801 802 Nacional de Biotecnología (CSIC), 28049 Madrid, Spain; 803 () orcid.org/0000-0002-9070-1024;

Email: ali.abou_hassan@sorbonne-universite.fr MSC, UMR 7057, CNRS and University of Paris, 75205807 Paris, Cedex 13, France; Laboratoire PhysicoChimie Curie, 808 Institut Curie, PSL Research University-Sorbonne 809 Université-CNRS, 75005 Paris, France; Nanobiotecnología 810 (IMDEA-Nanociencia), Unidad Asociada al Centro 811 Nacional de Biotecnología (CSIC), 28049 Madrid, Spain; 812 (ㄱ) orcid.org/0000-0001-7024-9627;

Email: claire.wilhelm@univ-paris-diderot.fr

Alberto Curcio - Laboratoire Matiere et Systèmes Complexes 816 MSC, UMR 7057, CNRS and University of Paris, 75205817 Paris, Cedex 13, France; Laboratoire PhysicoChimie Curie, 818 Institut Curie, PSL Research University-Sorbonne 819 Université-CNRS, 75005 Paris, France

Aurore Van de Walle - Laboratoire Matière et Systèmes 821 Complexes MSC, UMR 7057, CNRS and University of Paris, 822 75205 Paris, Cedex 13, France; Laboratoire PhysicoChimie 823 Curie, Institut Curie, PSL Research University-Sorbonne 824 Université-CNRS, 75005 Paris, France 825

Emilia Benassai - Laboratoire Matière et Systèmes Complexes 826 MSC, UMR 7057, CNRS and University of Paris, 75205827 Paris, Cedex 13, France; Sorbonne Université, CNRS 828 UMR234, PHysico-chimie des Electrolytes et Nanosystèmes 829 InterfaciauX, PHENIX, F-75005 Paris, France 830

Aida Serrano - Spanish CRG beamline at the European 831 Synchrotron (ESRF), F-38043 Grenoble, France; 832 Departamento de Electrocerámica, Instituto de Cerámica y 833 Vidrio, 28049 Madrid, Spain; (1) orcid.org/0000-0002- 834 6162-0014

Nathalie Luciani - Laboratoire Matière et Systèmes 836 Complexes MSC, UMR 7057, CNRS and University of Paris, 837 75205 Paris, Cedex 13, France

838

Nicolas Menguy - Sorbonne Université, UMR CNRS 7590, 839 MNHN, IRD, Institut de Minéralogie, de Physique des 840 Matériaux et de Cosmochimie, IMPMC, 75005 Paris, France 841

Bella B. Manshian - NanoHealth and Optical Imaging 842 Group, Department of Imaging and Pathology, KU Leuven, 843 B3000 Leuven, Belgium; (1) orcid.org/0000-0002-3402- 844 3927

Ara Sargsian - NanoHealth and Optical Imaging Group, $\quad 846$ Department of Imaging and Pathology, KU Leuven, B3000 847 Leuven, Belgium

Stefaan Soenen - NanoHealth and Optical Imaging Group, 849 Department of Imaging and Pathology, KU Leuven, B3000 850 Leuven, Belgium; Oorcid.org/0000-0003-2390-3133 851

Ana Espinosa - Nanobiotecnología (IMDEA-Nanociencia), $\quad 852$ Unidad Asociada al Centro Nacional de Biotecnología 853 
854 (CSIC), 28049 Madrid, Spain; 이잉.org/0000-0002$855 \quad 5626-6129$

856 Complete contact information is available at: 857 https://pubs.acs.org/10.1021/acsnano.1c00567

\section{Notes}

859 The authors declare no competing financial interest.

\section{ACKNOWLEDGMENTS}

861 This work was supported by the European Union (ERC-2014862 CoG project MaTissE 648779 and ERC-2019-CoG project 863 NanoBioMade 865629). A.V. acknowledges financial support 864 from the CNRS through the MITI interdisciplinary programs 865 Métallo-Mix (project BioMade), and A.E. and A.S. acknowl866 edge support from the Comunidad de Madrid for the 867 "Atracción de Talento Investigador" contracts (Nos. 2018$868 \mathrm{~T} 1 /$ IND10058 and 2017-T2/IND5395). The authors thank 869 Christine Péchoux for the TEM imaging (platform TEM, 870 INRA, Jouy-en-Josas), the ESRF for beam time, and the CRG 871 beamline BM25-SpLine personnel for technical support.

\section{REFERENCES}

873 (1) Giner-Casares, J. J.; Henriksen-Lacey, M.; Coronado-Puchau, 874 M.; Liz-Marzán, L. M. Inorganic Nanoparticles for Biomedicine: 875 Where Materials Scientists Meet Medical Research. Mater. Today 876 2016, 19 (1), 19-28.

(2) Bakhtiary, Z.; Saei, A. A.; Hajipour, M. J.; Raoufi, M.; Vermesh, 878 O.; Mahmoudi, M. Targeted Superparamagnetic Iron Oxide Nano879 particles for Early Detection of Cancer: Possibilities and Challenges. 880 Nanomedicine 2016, 12 (2), 287-307.

881 (3) Pelaz, B.; Alexiou, C.; Alvarez-Puebla, R. A.; Alves, F.; Andrews, 882 A. M.; Ashraf, S.; Balogh, L. P.; Ballerini, L.; Bestetti, A.; Brendel, C.; 883 Bosi, S.; Carril, M.; Chan, W. C. W.; Chen, C.; Chen, X.; Chen, X.; 884 Cheng, Z.; Cui, D.; Du, J.; Dullin, C.; et al. Diverse Applications of 885 Nanomedicine. ACS Nano 2017, 11 (3), 2313-2381.

886 (4) Patino, T.; Mahajan, U.; Palankar, R.; Medvedev, N.; Walowski, 887 J.; Münzenberg, M.; Mayerle, J.; Delcea, M. Multifunctional Gold 888 Nanorods for Selective Plasmonic Photothermal Therapy in 889 Pancreatic Cancer Cells Using Ultra-Short Pulse Near-Infrared 890 Laser Irradiation. Nanoscale 2015, 7 (12), 5328-5337.

891 (5) Espinosa, A.; Reguera, J.; Curcio, A.; Muñoz-Noval, Á.; Kuttner, 892 C.; Van de Walle, A.; Liz-Marzán, L. M.; Wilhelm, C. Janus Magnetic893 Plasmonic Nanoparticles for Magnetically Guided and Thermally 894 Activated Cancer Therapy. Small 2020, 16 (11), 1904960.

895 (6) Rastinehad, A. R.; Anastos, H.; Wajswol, E.; Winoker, J. S.; 896 Sfakianos, J. P.; Doppalapudi, S. K.; Carrick, M. R.; Knauer, C. J.; 897 Taouli, B.; Lewis, S. C.; Tewari, A. K.; Schwartz, J. A.; Canfield, S. E.; 898 George, A. K.; West, J. L.; Halas, N. J. Gold Nanoshell-Localized 899 Photothermal Ablation of Prostate Tumors in a Clinical Pilot Device 900 Study. Proc. Natl. Acad. Sci. U. S. A. 2019, 116 (37), 18590-18596. 901 (7) Martina, M.-S.; Wilhelm, C.; Lesieur, S. The Effect of Magnetic 902 Targeting on the Uptake of Magnetic-Fluid-Loaded Liposomes by 903 Human Prostatic Adenocarcinoma Cells. Biomaterials 2008, 29 (30), 904 4137-4145.

905 (8) Soenen, S. J.; Parak, W. J.; Rejman, J.; Manshian, B. (Intra) 906 Cellular Stability of Inorganic Nanoparticles: Effects on Cytotoxicity, 907 Particle Functionality, and Biomedical Applications. Chem. Rev. 2015, 908115 (5), 2109-2135.

909 (9) Caracciolo, G.; Vali, H.; Moore, A.; Mahmoudi, M. Challenges 910 in Molecular Diagnostic Research in Cancer Nanotechnology. Nano 911 Today 2019, 27, 6-10.

912 (10) Chen, C.; Leong, D. T.; Lynch, I. Rethinking Nanosafety: 913 Harnessing Progress and Driving Innovation. Small 2020, 16 (21), 9142002503.
(11) Carril, M.; Padro, D.; Del Pino, P.; Carrillo-Carrion, C.; 915 Gallego, M.; Parak, W. J. In Situ Detection of the Protein Corona in 916 Complex Environments. Nat. Commun. 2017, 8 (1), 1-5. 917 (12) Mahmoudi, M.; Bertrand, N.; Zope, H.; Farokhzad, O. C. 918 Emerging Understanding of the Protein Corona at the Nano-Bio 919 Interfaces. Nano Today 2016, 11 (6), 817-832.

920

(13) Ashkarran, A. A.; Dararatana, N.; Crespy, D.; Caracciolo, G.; 921 Mahmoudi, M. Mapping the Heterogeneity of Protein Corona by ex 922 Vivo Magnetic Levitation. Nanoscale 2020, 12 (4), 2374-2383. 923

(14) Sharifi, S.; Caracciolo, G.; Mahmoudi, M. Biomolecular Corona 924 Affects Controlled Release of Drug Payloads from Nanocarriers. 925 Trends Pharmacol. Sci. 2020, 41, 641.

926

(15) Kittler, S.; Greulich, C.; Diendorf, J.; Koller, M.; Epple, M. 927 Toxicity of Silver Nanoparticles Increases during Storage Because of 928 Slow Dissolution under Release of Silver Ions. Chem. Mater. 2010, 22929 (16), 4548-4554.

930

(16) Wen, R.; Hu, L.; Qu, G.; Zhou, Q.; Jiang, G. Exposure, Tissue 931 Biodistribution, and Biotransformation of Nanosilver. NanoImpact 932 2016, 2, 18-28. 933

(17) Yue, Y.; Behra, R.; Sigg, L.; Suter, M. J.-F.; Pillai, S.; Schirmer, 934 K. Silver Nanoparticle-Protein Interactions in Intact Rainbow Trout 935 Gill Cells. Environ. Sci.: Nano 2016, 3 (5), 1174-1185. 936

(18) Liu, Z.; Escudero, A.; Carrillo-Carrion, C.; Chakraborty, I.; 937 Zhu, D.; Gallego, M.; Parak, W. J.; Feliu, N. Biodegradation of Bi- 938 Labeled Polymer-Coated Rare-Earth Nanoparticles in Adherent Cell 939 Cultures. Chem. Mater. 2020, 32 (1), 245-254. 940

(19) Bargheer, D.; Giemsa, A.; Freund, B.; Heine, M.; Waurisch, C.; 941 Stachowski, G. M.; Hickey, S. G.; Eychmüller, A.; Heeren, J.; Nielsen, 942 P. The Distribution and Degradation of Radiolabeled Super- 943 paramagnetic Iron Oxide Nanoparticles and Quantum Dots in 944 Mice. Beilstein J. Nanotechnol. 2015, 6 (1), 111-123.

(20) Gilbert, B.; Fakra, S. C.; Xia, T.; Pokhrel, S.; Mädler, L.; Nel, A. 946 E. The Fate of Zno Nanoparticles Administered to Human Bronchial 947 Epithelial Cells. ACS Nano 2012, 6 (6), 4921-4930. 948

(21) James, S. A.; Feltis, B. N.; de Jonge, M. D.; Sridhar, M.; 949 Kimpton, J. A.; Altissimo, M.; Mayo, S.; Zheng, C.; Hastings, A.; 950 Howard, D. L. Quantification of Zno Nanoparticle Uptake, 951 Distribution, and Dissolution within Individual Human Macrophages. 952 ACS Nano 2013, 7 (12), 10621-10635. 953

(22) Roy, S.; Liu, Z.; Sun, X.; Gharib, M.; Yan, H.; Huang, Y.; 954 Megahed, S.; Schnabel, M.; Zhu, D.; Feliu, N. Assembly and 955 Degradation of Inorganic Nanoparticles in Biological Environments. 956 Bioconjugate Chem. 2019, 30 (11), 2751-2762.

(23) Sangnier, A. P.; Van de Walle, A. B.; Curcio, A.; Le Borgne, R.; 958 Motte, L.; Lalatonne, Y.; Wilhelm, C. Impact of Magnetic Nano- 959 particle Surface Coating on Their Long-Term Intracellular Biode- 960 gradation in Stem Cells. Nanoscale 2019, 11 (35), 16488-16498. 961

(24) Sharma, S.; Shrivastava, N.; Rossi, F.; Thanh, N. T. K. 962 Nanoparticles-Based Magnetic and Photo Induced Hyperthermia for 963 Cancer Treatment. Nano Today 2019, 29, 100795.

(25) Espinosa, A.; Curcio, A.; Cabana, S.; Radtke, G.; Bugnet, M.; 965 Kolosnjaj-Tabi, J.; Péchoux, C.; Alvarez-Lorenzo, C.; Botton, G. A.; 966 Silva, A. K.; Abou-Hassan, A.; Wilhelm, C. Intracellular Biodegrada- 967 tion of Ag Nanoparticles, Storage in Ferritin, and Protection by a Au 968 Shell for Enhanced Photothermal Therapy. ACS Nano 2018, 12 (7), 969 6523-6535.

(26) Mazuel, F.; Espinosa, A.; Radtke, G.; Bugnet, M.; Neveu, S.; 971 Lalatonne, Y.; Botton, G. A.; Abou-Hassan, A.; Wilhelm, C. Magneto- 972 Thermal Metrics Can Mirror the Long-Term Intracellular Fate of 973 Magneto-Plasmonic Nanohybrids and Reveal the Remarkable 974 Shielding Effect of Gold. Adv. Funct. Mater. 2017, 27 (9), 1605997. 975 (27) Zhuo, X.; Henriksen-Lacey, M.; Jimenez de Aberasturi, D.; 976 Sánchez-Iglesias, A.; Liz-Marzán, L. M. Shielded Silver Nanorods for 977 Bioapplications. Chem. Mater. 2020, 32 (13), 5879-5889. 978

(28) Kreyling, W. G.; Abdelmonem, A. M.; Ali, Z.; Alves, F.; Geiser, 979 M.; Haberl, N.; Hartmann, R.; Hirn, S.; De Aberasturi, D. J.; Kantner, 980 K. In Vivo Integrity of Polymer-Coated Gold Nanoparticles. Nat. 981 Nanotechnol. 2015, 10 (7), 619-623. 
983 (29) Goodman, A. M.; Cao, Y.; Urban, C.; Neumann, O.; Ayala984 Orozco, C.; Knight, M. W.; Joshi, A.; Nordlander, P.; Halas, N. J. The 985 Surprising in Vivo Instability of Near-IR-Absorbing Hollow Au-Ag 986 Nanoshells. ACS Nano 2014, 8 (4), 3222-3231.

987 (30) Van de Walle, A.; Kolosnjaj-Tabi, J.; Lalatonne, Y.; Wilhelm, C. 988 Ever-Evolving Identity of Magnetic Nanoparticles within Human 989 Cells, the Interplay of Endosomal Confinement, Degradation, Storage, 990 and Neo-Crystallization. Acc. Chem. Res. 2020, 53 (10), 2212-2224. 991 (31) Curcio, A.; Van de Walle, A.; Serrano, A.; Prévéral, S.; Pechoux, 992 C.; Pignol, D.; Menguy, N.; Lefevre, C. T.; Espinosa, A.; Wilhelm, C. 993 Transformation Cycle of Magnetosomes in Human Stem Cells: From 994 Degradation to Biosynthesis of Magnetic Nanoparticles Anew. ACS 995 Nano 2020, 14 (2), 1406-1417.

996 (32) Gai, S.; Yang, G.; Yang, P.; He, F.; Lin, J.; Jin, D.; Xing, B. 997 Recent Advances in Functional Nanomaterials for Light-Triggered 998 Cancer Therapy. Nano Today 2018, 19, 146-187.

999 (33) Curcio, A.; Silva, A. K.; Cabana, S.; Espinosa, A.; Baptiste, B.; 1000 Menguy, N.; Wilhelm, C.; Abou-Hassan, A. Iron Oxide Nano1001 flowers@ CuS Hybrids for Cancer Tri-Therapy: Interplay of 1002 Photothermal Therapy, Magnetic Hyperthermia and Photodynamic 1003 Therapy. Theranostics 2019, 9 (5), 1288.

1004 (34) Wang, S.; Riedinger, A.; Li, H.; Fu, C.; Liu, H.; Li, L.; Liu, T.; 1005 Tan, L.; Barthel, M. J.; Pugliese, G. Plasmonic Copper Sulfide 1006 Nanocrystals Exhibiting Near-Infrared Photothermal and Photo1007 dynamic Therapeutic Effects. ACS Nano 2015, 9 (2), 1788-1800.

1008 (35) Marin, R.; Skripka, A.; Besteiro, L. V.; Benayas, A.; Wang, Z.; 1009 Govorov, A. O.; Canton, P.; Vetrone, F. Highly Efficient Copper 1010 Sulfide-Based Near-Infrared Photothermal Agents: Exploring the 1011 Limits of Macroscopic Heat Conversion. Small 2018, 14 (49), 10121803282.

1013 (36) Li, L.; Rashidi, L. H.; Yao, M.; Ma, L.; Chen, L.; Zhang, J.; 1014 Zhang, Y.; Chen, W. CuS Nanoagents for Photodynamic and 1015 Photothermal Therapies: Phenomena and Possible Mechanisms. 1016 Photodiagn. Photodyn. Ther. 2017, 19, 5-14.

1017 (37) Ramadan, S.; Guo, L.; Li, Y.; Yan, B.; Lu, W. Hollow Copper 1018 Sulfide Nanoparticle-Mediated Transdermal Drug Delivery. Small 1019 2012, 8 (20), 3143-3150.

1020 (38) Chen, L.; Hu, H.; Chen, Y.; Gao, J.; Li, G. Plasmonic Cu 2- X S 1021 Nanoparticles: A Brief Introduction of Optical Properties and 1022 Applications. Materials Advances 2021, 2, 907-926.

1023 (39) Wang, D.; Dong, H.; Li, M.; Cao, Y.; Yang, F.; Zhang, K.; Dai, 1024 W.; Wang, C.; Zhang, X. Erythrocyte-Cancer Hybrid Membrane 1025 Camouflaged Hollow Copper Sulfide Nanoparticles for Prolonged 1026 Circulation Life and Homotypic-Targeting Photothermal/Chemo1027 therapy of Melanoma. ACS Nano 2018, 12 (6), 5241-5252.

1028 (40) Guo, L.; Panderi, I.; Yan, D. D.; Szulak, K.; Li, Y.; Chen, Y.-T.; 1029 Ma, H.; Niesen, D. B.; Seeram, N.; Ahmed, A. A Comparative Study 1030 of Hollow Copper Sulfide Nanoparticles and Hollow Gold Nano1031 spheres on Degradability and Toxicity. ACS Nano 2013, 7 (10), $10328780-8793$.

1033 (41) Ortiz de Solorzano, I.; Prieto, M.; Mendoza, G.; Alejo, T.; 1034 Irusta, S.; Sebastian, V.; Arruebo, M. Microfluidic Synthesis and 1035 Biological Evaluation of Photothermal Biodegradable Copper Sulfide 1036 Nanoparticles. ACS Appl. Mater. Interfaces 2016, 8 (33), 21545103721554.

1038 (42) Corradini, E.; Bernardis, I.; Dongiovanni, P.; Buzzetti, E.; 1039 Caleffi, A.; Artuso, L.; Pelusi, S.; Tenedini, E.; Tagliafico, E.; Rametta, 1040 R. Rare Ceruloplasmin Variants Are Associated with Hyper1041 ferritinemia and Increased Hepatic Iron in Nafld Patients: Results 1042 from a Ngs Study. J. Hepatol. 2018, 68, S58-S59.

1043 (43) Zhu, S.; Shanbhag, V.; Wang, Y.; Lee, J.; Petris, M. A Role for 1044 the Atp7a Copper Transporter in Tumorigenesis and Cisplatin 1045 Resistance. J. Cancer 2017, 8 (11), 1952.

1046 (44) Gu, J.; Xu, H.; Han, Y.; Dai, W.; Hao, W.; Wang, C.; Gu, N.; 1047 Xu, H.; Cao, J. The Internalization Pathway, Metabolic Fate and 1048 Biological Effect of Superparamagnetic Iron Oxide Nanoparticles in 1049 the Macrophage-Like Raw264. 7 Cell. Sci. China: Life Sci. 2011, 54 1050 (9), 793-805.
(45) Kurz, T.; Terman, A.; Gustafsson, B.; Brunk, U. T. Lysosomes 1051 in Iron Metabolism, Ageing and Apoptosis. Histochem. Cell Biol. 2008, 1052 129 (4), 389-406.

1053

(46) Soenen, S. J.; Demeester, J.; De Smedt, S. C.; Braeckmans, K. 1054 Turning a Frown Upside Down: Exploiting Nanoparticle Toxicity for 1055 Anticancer Therapy. Nano Today 2013, 8 (2), 121-125. 1056

(47) Kaplan, J. H.; Maryon, E. B. How Mammalian Cells Acquire 1057 Copper: An Essential but Potentially Toxic Metal. Biophys. J. 2016, 1058 110 (1), 7-13.

1059

(48) Liu, S.; Liu, Y.; Pan, B.; He, Y.; Li, B.; Zhou, D.; Xiao, Y.; Qiu, 1060 H.; Vijver, M. G.; Peijnenburg, W. J. The Promoted Dissolution of 1061 Copper Oxide Nanoparticles by Dissolved Humic Acid: Copper 1062 Complexation over Particle Dispersion. Chemosphere 2020, 245, 1063 125612 .

1064

(49) Naatz, H.; Manshian, B. B.; Rios Luci, C.; Tsikourkitoudi, V.; 1065 Deligiannakis, Y.; Birkenstock, J.; Pokhrel, S.; Mädler, L.; Soenen, S. J. 1066 Model-Based Nanoengineered Pharmacokinetics of Iron-Doped 1067 Copper Oxide for Nanomedical Applications. Angew. Chem. 2020, 1068 132 (5), 1844-1852.

1069

(50) Hugounenq, P.; Levy, M.; Alloyeau, D.; Lartigue, L.; Dubois, 1070 E.; Cabuil, V. R.; Ricolleau, C.; Roux, S. P.; Wilhelm, C.; Gazeau, F. 1071 Iron Oxide Monocrystalline Nanoflowers for Highly Efficient 1072 Magnetic Hyperthermia. J. Phys. Chem. C 2012, 116 (29), 15702- 1073 15712 .

1074

(51) Ravel, B.; Newville, M. Athena, Artemis, Hephaestus: Data 1075 Analysis for X-Ray Absorption Spectroscopy Using Ifeffit. J. 1076 Synchrotron Radiat. 2005, 12 (4), 537-541.
1077 